\title{
Effect of fracture roughness on the hydrodynamics of proppant transport in hydraulic fractures.
}

SURI, Y. ISLAM, S.Z. and HOSSAIN, M. 


\title{
Effect of Fracture Roughness on the hydrodynamics of proppant transport in hydraulic fractures
}

\author{
Yatin Suri, Sheikh Zahidul Islam*, and Mamdud Hossain \\ School of Engineering, Robert Gordon University, Aberdeen, AB10 7GJ, UK \\ *Corresponding author. Email: s.z.islam1@rgu.ac.uk \\ Phone: $+44(0) 1224262319$ \\ Fax: $+44(0) 1224262444$
}

\section{Abstract-}

The effect of fracture roughness is investigated on proppant transport in hydraulic fractures using Joint Roughness Coefficient and a three-dimensional multiphase modelling approach. The equations governing the proppant transport physics in the fracturing fluid is solved using the hybrid computational fluid dynamics model. The reported proppant transport models in the literature are limited to the assumption of a smooth fracture domain with no fluid leak-off or fluid flow from fracture to rock matrix interface. In this paper, a proppant transport model is proposed that accounts for the proppant distribution in rough fracture geometry with fluid leakoff effect to surrounding porous rock. The hydrodynamic and mechanical behaviour of proppant transport was found directly related to the fracture roughness and flow regime especially under the influence of low viscosity fracturing fluid typically used in shale gas reservoirs. For the proppant transport in smooth fractures, the fracture walls employ mechanical retardation effects and reduce the proppant horizontal velocity resulting in more significant proppant deposition. On the contrary, for the proppant transport in rough fractures, the interproppant and proppant wall interactions become dominant that adds turbulence to the flow. It results in mechanical interaction flow effects becoming dominant and consequently higher proppants suspended in the slurry and greater horizontal transport velocity. Furthermore, the mechanical interaction flow effects were found to be principally dependant on the proppant transport regime and become significant at higher proppant Reynolds number.

\section{Keywords}

Joint roughness coefficient; Computational Fluid Dynamics; Hydraulic fracturing; Fluid Leak-off; Proppant transport; Fracture Roughness

\section{Highlights}

- Effect of fracture roughness investigated on proppant transport and distribution

- $\quad$ Fracture roughness modelled using Joint Roughness Coefficient (JRC)

- Mechanical interaction effects become dominant at higher JRC and Reynolds number
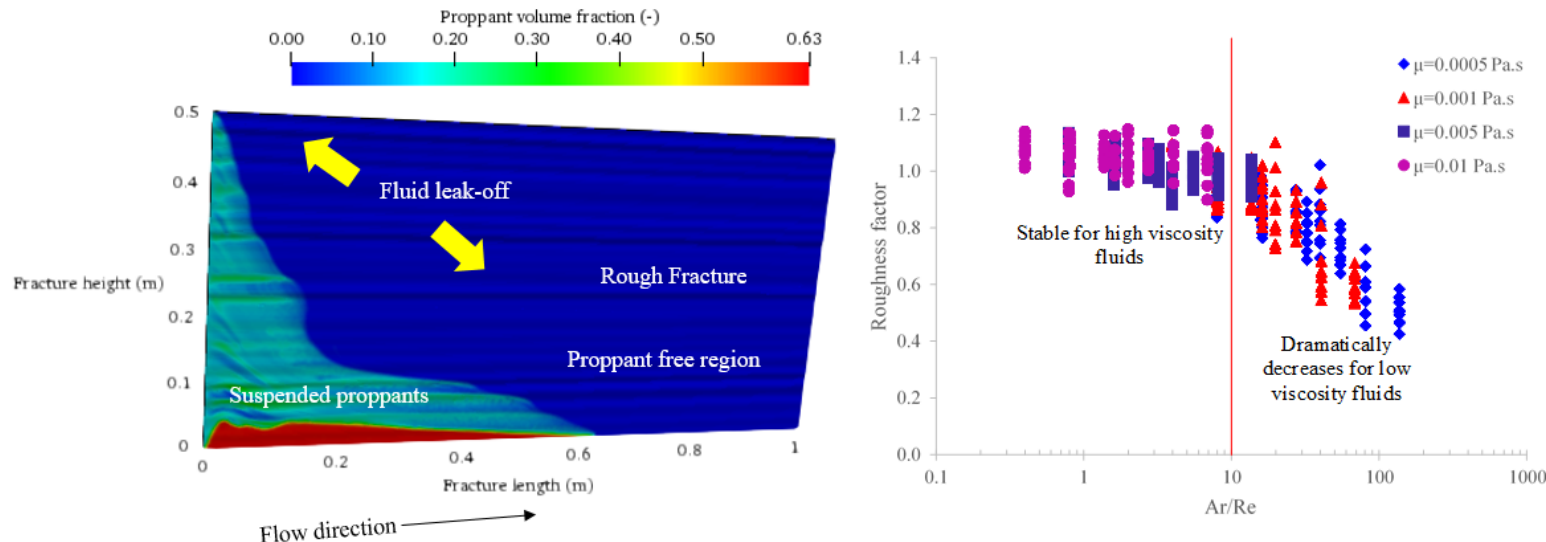
Solid transport with fluid in the form of slurry flow is widespread in several diverse applications, like sand transport in the river, wastewater disposal, petroleum engineering or proppant transport during hydraulic fracturing, and fluidized-bed reactors (Chalov et al., 2015; Sahu et al., 2013; Tong and Mohanty, 2016). In all the applications, the discrete phase, i.e. solid, is suspended in the continuous phase, i.e. fluid, and frequent momentum transfer occurs between both the phases (Dontsov and Peirce, 2014). The three critical physical phenomena that affect the hydrodynamics of particle transport in the fluid are a fluid drag, particle settlement and particle-wall interaction (Patankar and Joseph, 2001). The continuous phase exerts a drag force on the particles and changes the particle transport velocity. Due to the drag force and the energy dissipation, the particle travels slowly compared to the fluid, and this results in slippage velocity (Zhang et al., 2017). This particle-fluid coupling adds complexity to the flow. In addition, based on the concentration of the suspended particles, the inter-particle collision can significantly affect the transport phenomenon (Blyton et al., 2015). The higher inter-particle collision can be dominant in the dense phase transport that increases the randomness and turbulence in the flow adding further complexity (Blyton et al., 2015). Lastly, for the slurry flow in rough wall surfaces, the irregular wall results in higher particle-wall interactions and significantly increases the flow disturbance affecting the hydrodynamic and mechanical properties of solid transport (Zhang et al., 2019b). Zhang et al. (2019a) comprehensively investigated the effect of $2 \mathrm{D}$ rough fractures on single-phase fluid flow and microflow effects, i.e. when the fracture aperture approaches the mean free path of fluid molecules. It was proposed that the fracture roughness significantly alters the relationship between the hydraulic and mechanical apertures, which further affects the velocity and pressure fields inside the fracture.

In the petroleum industry, hydraulic fracturing is one of the widely used technology for hydrocarbon production, particularly in shale gas reservoirs (Veatch et al., 2017). The process of hydraulic fracturing includes injection of high-pressure fluid (or fracturing fluid) into the subsurface rock through the wellbore, to create fractures or cracks (Uddameri et al., 2015). The purpose of these fractures is to provide a conductive path for the hydrocarbons to enter the wellbore or to increase the connectivity of the existing fractures (Speight, 2016). Post creation of the fractures, solid particles like sand are dispersed in fluid, and the slurry is injected. The solid particles are known as proppants. The key role of injecting proppants is firstly to prevent the fracture from closing when the hydraulic pressure is removed, and secondly to provide the adequate flow conductivity from the tight reservoir to the wellbore (Smith and Montgomery, 2015). Particularly, in shale gas reservoirs, the slick water fracturing fluid is most commonly used for conducting hydraulic fracturing (Suri et al., 2019). Due to the low viscosity of the slick water fracturing fluid, it possesses a poor ability to suspend proppants (Sahai et al., 2014). The productivity of the hydraulically fractured wells is dependent on the propped fractures, which is driven by the proppant settlement and transport inside the fractures (Bokane et al., 2014). Typically, the fracture aperture is around $3 \mathrm{~mm}-10 \mathrm{~mm}$. During the transport of the fracturing fluid slurry suspended with proppants in the narrow fracture opening, the fracture walls exert a mechanically induced flow effect that influences the proppant transport velocity and proppant settlement (Zhang et al., 2019b). Thus, the frequent proppant-fluid, inter-proppant and proppant-rough wall interactions lead to a complex proppant transport physics in fracturing fluid flow. This complex phenomenon leads to the current study of fracture roughness in the proppant transport model appealing to petroleum engineers and researchers (Deshpande et al., 2013).

Particles settling in cylinder tubes have frequently been investigated (Arsenijević et al., 2010; Chhabra et al., 2003; Delidis and Stamatoudis, 2009). The wall factor, which is the ratio of the particle terminal velocities in bounded and unbounded fluids, is typically defined to determine the hydrodynamic drag force on particles. From the literature, it is recognised that the wall factor for spheres settling in a fluid is mainly dependant on the size ratio of the sphere diameter 
to the inner tube diameter and the Reynolds number. Recently, Malhotra and Sharma (2012) and Zhang et al. (2016) investigated the settling velocity of spherical particles between two parallel plates for Newtonian and non-Newtonian fluids. However, the surface of the plates was assumed as smooth, and no effect of fracture roughness was studied.

The multiphase flow of fracturing fluid and proppants in the hydraulic fracture can be categorised into three regions contingent on the inter-proppant association: negligible collision flow, predominant collision flow and predominant contact flow. In the region where the flow is predominantly governed by collision, the interaction between proppant-fluid, proppantproppant and proppant-rough fracture wall need to be accurately modelled.

To numerically simulate the multiphase slurry flow where the solid particles are suspended in the fluid is mainly modelled using following two numerical modelling techniques. Firstly, the Eulerian-Lagrangian technique tracks the trajectory of individual particles and models accurately the inter-proppant interaction or collision, and proppant-wall interaction. Secondly, the Eulerian-Granular method models the average behaviour of proppants and calculates overall diffusion and convection of a group of proppants based on empirical relationships or kinetic theory of granular flow. The computational time required for solving the proppant transport physics using the Eulerian-Lagrangian method is substantially higher as it tracks the motion of individual particles, and thus this method is less appealing for simulating field scale fractures. In the current study, a hybrid model is used (Suri et al., 2019), which tracks the trajectory of individual proppants based on Eulerian-Lagrangian method, but models the proppant-fluid and inter-proppant physics using the kinetic theory of granular flow based on Eulerian Granular method. The method is computationally less expensive compared to Eulerian-Lagrangian method and captures the hydrodynamics of proppant transport accurately.

The hydrodynamics of proppant transport in fractures is a complex process, and the factors like fracture geometry, fracture roughness, and fluid leak-off add additional challenges to model the flow phenomenon numerically. In recent years, several researchers have modelled the proppant transport physics in hydraulic fractures using computational fluid dynamics (CFD) technique. Zhang and Dunn-Norman (2015) examined the proppant distribution at different perforation angle in fractures or the inclination at which the fractures were created and compared the pressure drop using CFD. Kou et al. (2018) investigated the proppant transport and distribution in the hydraulic fracture and natural fracture intersection using the discrete element method (CFD-DEM model). Hu et al. (2018) proposed an idea of using Eulerian-Eulerian proppant transport model for field-scale hydraulic fractures using dimension reduction strategy. The reported studies are limited to the assumption of smooth planar fracture geometry with no leakoff effects from the fracture wall. The fracture roughness coupled with fluid leak-off can significantly impact the proppant transport physics. Zhang et al. (2019b) investigated the Joint Roughness Coefficient (JRC) fracture profiles and proposed a proppant transport model in rough fractures. However, the model is limited to two-dimensional fracture geometry, and gravitational effects along with fluid-leak off effects were ignored. The existing proppant transport models are limited to modelling proppant hydrodynamics in smooth two-dimensional fracture geometry with no fluid leak-off from the fracture to the surrounding reservoir. Barton and Choubey (1977) proposed the joint roughness coefficient to characterise fracture roughness and predict the shear strength of different rock type. In the current study, the approach used by Barton and Choubey (1977) of joint roughness coefficient is further developed to investigate its effect on the fluid flow and proppant hydrodynamics comprehensively. A three-dimensional proppant transport model is proposed that accurately models the proppant transport physics in rough fractures and successfully configures the fluid flow from fracture sidewall to surrounding porous rock. The rough fracture profiles are created using the JRC described later in section 2.1. Subsequently, the dimensional analysis is carried out to identify the relationship between the critical dimensionless flow parameters and proppant transport regime. It is followed by a comparison of the proposed hybrid model against the published experimental results. Lastly, a comprehensive investigation of proppant transport in smooth and rough fractures with dimensionless parameters is presented. 


\section{Model development-}

The principal aim of the present work is to extensively investigate the impact of fracture roughness on the hydrodynamics of proppant transport during hydraulic fracturing. A hybrid (CFD-DEM) numerical model is used to solve this multiphase flow problem in rough fracture profiles coupled with the effect of fluid leak-off from the fracture wall.

\subsection{Problem formulation and Joint Roughness Coefficient profiles}

Barton and Choubey (1977) were among the early researchers who studied the fracture roughness in detail and proposed a parameter called Joint Roughness Coefficient (JRC), denoted by $\Theta_{J R C}$, to differentiate the rough fractures. The equation for JRC is defined by Eq. (1)

$$
\Theta_{J R C}=\frac{\tan ^{-1}\left(\frac{\tau}{\sigma_{n}}\right)-\Phi_{b}}{\log \left(\frac{\sigma_{c}}{\sigma_{n}}\right)}
$$

Where $\tau$ is the maximum shear strength; $\sigma_{n}$ is the effective stress in the normal direction; $\Phi_{b}$ is the angle of friction; and $\sigma_{c}$ is fracture compressive strength. Barton and Choubey (1977) calculated the value of JRC for different rock types. The JRC value for calcareous shale was calculated as 8.2. More recently, Kassis and Sondergeld (2010) extracted the SEM image of a Barnett shale core sample in order to investigate the fracture roughness. The fracture roughness for the Barnett shale sample can be related to the JRC scale of Barton and Choubey (1977) in between 10-11. Furthermore, some of the smooth rock types analysed by Barton and Choubey (1977) are Slate and Gneiss whose JRC values range in between 2-6. The fracture profiles with different JRC values are shown in Fig. 1.

In the present study, three different rough fracture profiles were created with JRC values 4,8 and 16 using the published data by Barton and Choubey (1977) and the fractal theory proposed by Mandelbrot (1983). The fractal theory helps in characterising the randomly distributed irregular fracture surfaces resulting in fracture roughness with different JRC values (Alves, 2012). The rough fracture profiles were created based on the methodology from Briggs et al. (2017) and SynFrac software (Ogilvie et al., 2006). The JRC fracture profiles are displayed in Fig. 1 and are constructed such that the fracture aperture followed a normalised distribution curve shown in Fig. 2 with a mean aperture of $5 \mathrm{~mm}$ and a standard deviation of $0.1 \mathrm{~mm}$. The fracture domain in the present study has length $1.5 \mathrm{~m}$, aperture $5 \mathrm{~mm}$ and height $0.5 \mathrm{~m}$. In the present study, no dynamic fracture propagation is assumed. 


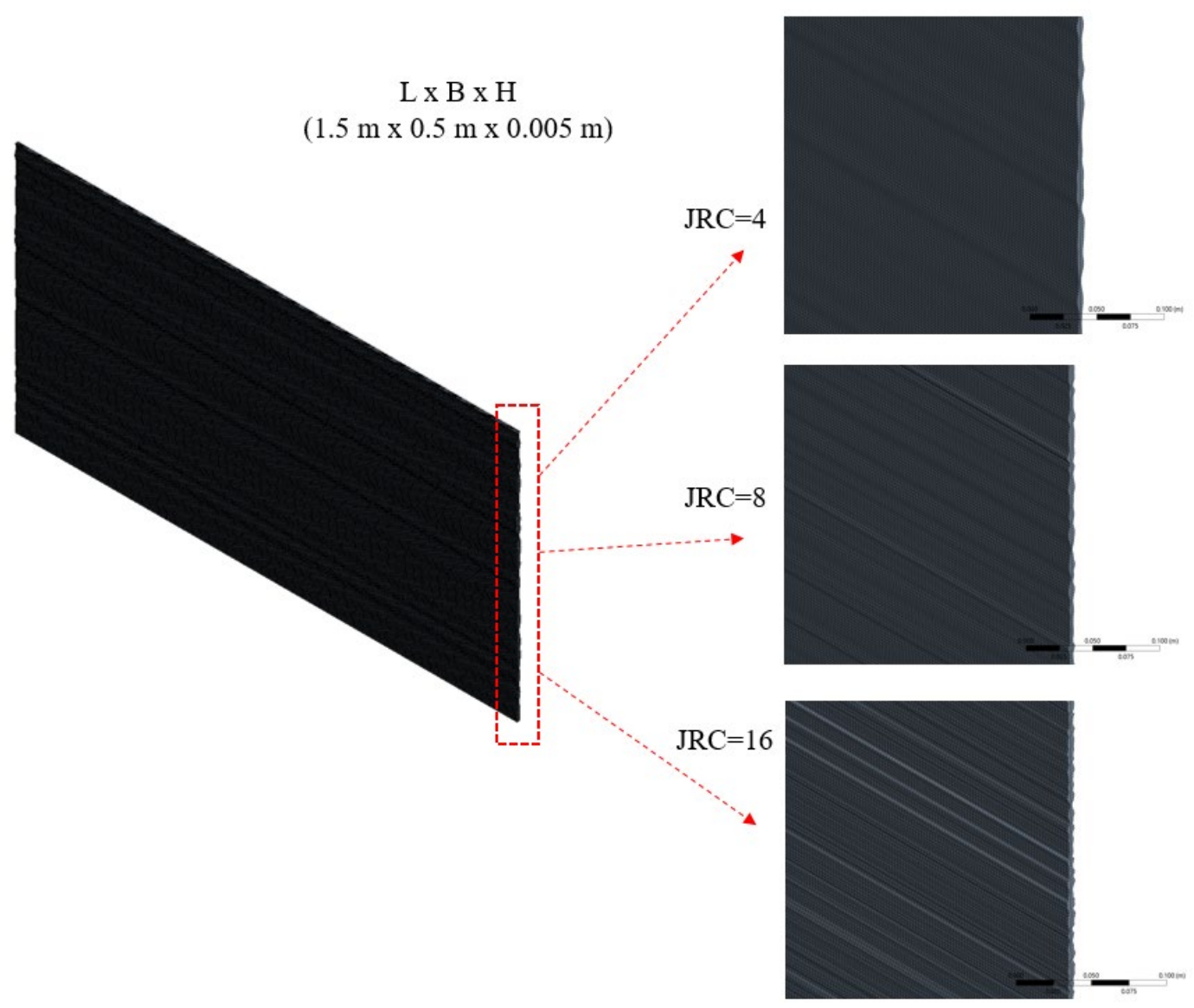

Fig. 1. Rough fracture geometries with different JRC values

190

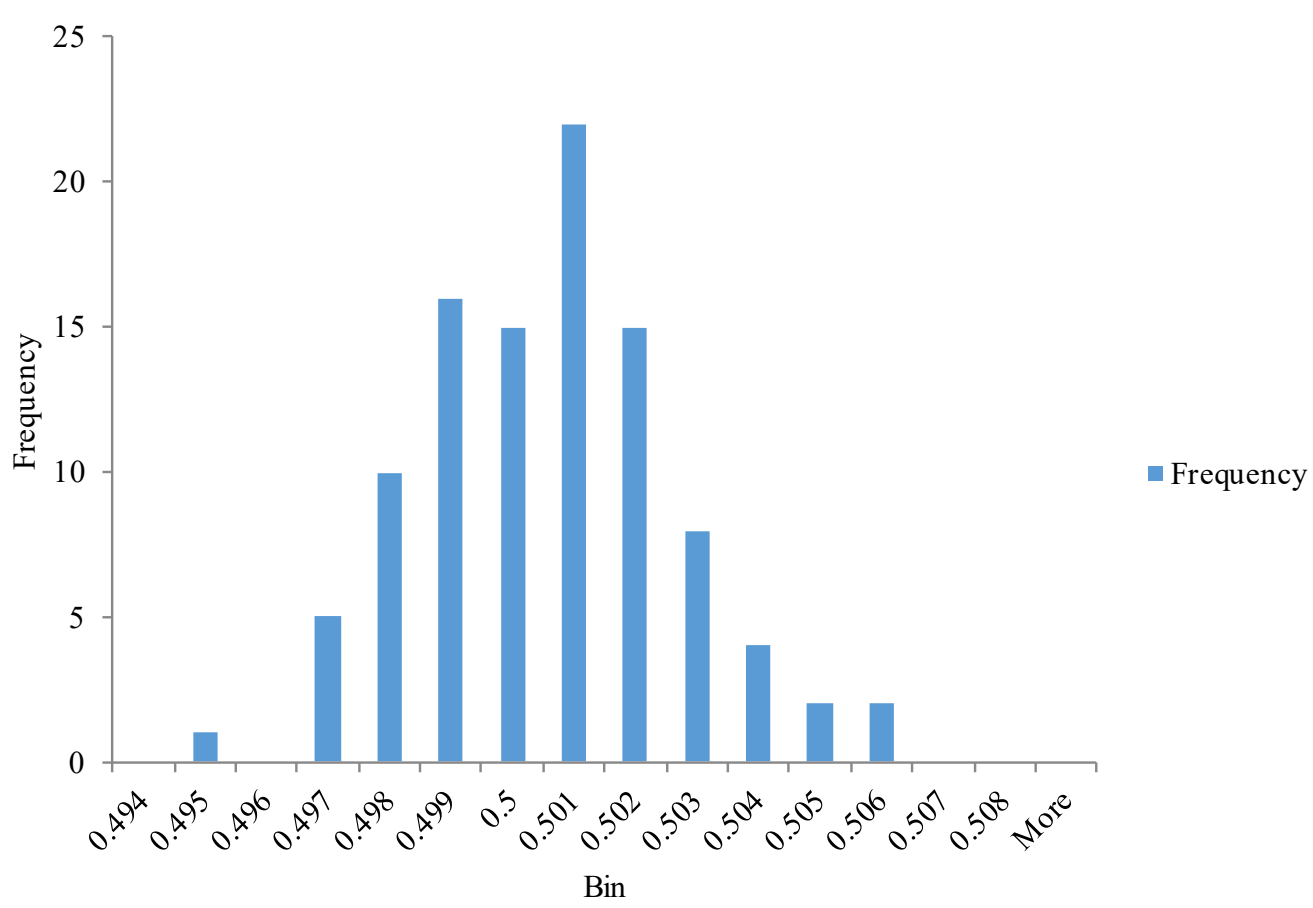

Fig. 2. Normal distribution curve to create a rough fracture profile 


\subsection{Mathematical model}

\subsubsection{Governing Equations}

As discussed earlier, the multiphase flow of fluid with suspended proppants can be numerically modelled using mainly two methods- Eulerian-Granular method and Eulerian-Langrangian method (or Discrete Element method). In order to take advantage of both these methods, a hybrid model is used in the current study that tracks the trajectory of individual proppants using Eulerian-Langrangian approach with the fluid-proppant and inter-proppant interactions modelled using the kinetic theory of granular flow from Eulerian-Granular method. The equations describing the hybrid model for proppant transport used in the current study are explained in detail in our previous work (Suri et al., 2019). However, the key governing equations are briefly described as follows-

The mass and momentum conservation equations are given by Eq. (2) and Eq. (3):

$$
\begin{gathered}
\rho_{\mathrm{i}}\left(\frac{\partial}{\partial \mathrm{t}} \alpha_{\mathrm{i}}+\nabla \cdot \alpha_{\mathrm{i}} \overrightarrow{\mathrm{v}}_{\mathrm{i}}\right)=\mathrm{S}_{\mathrm{m}} \\
\frac{\partial}{\partial \mathrm{t}}\left(\alpha_{1} \rho_{\mathrm{l}} \overrightarrow{\mathrm{v}}_{\mathrm{l}}\right)+\nabla \cdot\left(\alpha_{1} \rho_{\mathrm{l}} \overrightarrow{\mathrm{v}}_{\mathrm{l}}\right)=-\alpha_{\mathrm{l}} \nabla_{\mathrm{p}}+\nabla \cdot \overline{\overline{\mathrm{\tau}}}_{\mathrm{l}}+\alpha_{\mathrm{l}} \rho_{\mathrm{l}} \mathrm{g}+\overrightarrow{\mathrm{M}}_{\mathrm{ls}}+\mathrm{S}_{\mathrm{u}}
\end{gathered}
$$

Where $\alpha$ is the phase volume fraction, $S_{m}$ and $S_{u}$ are mass and momentum source term respectively, $\overline{\overline{\tau_{1}}}$ and $\overrightarrow{\mathrm{M}}_{\mathrm{ls}}$ are the tensor variable of stress-strain for fluid phase and momentum exchange term, respectively. $\rho, \mathrm{v}, \mathrm{g}$ are the density, velocity, and acceleration due to gravity respectively.

The trajectory of the proppant phase can be calculated based on Eq. (4)

$$
\frac{d \overrightarrow{v_{p}}}{d t}=\frac{\overrightarrow{v_{l}}-\overrightarrow{v_{p}}}{\tau_{\mathrm{r}}}+\frac{g\left(\rho_{\mathrm{p}}-\rho\right)}{\rho_{\mathrm{p}}}+\overrightarrow{\mathrm{F}}_{\mathrm{KTGF}}
$$

In the right-hand side of Eq. (4), the first term refers to drag force, the central term refers to the gravity force and the last term the force due to kinetic theory of granular flow. The velocity and hence the location of proppant phase can be calculated using Eq. (4) at every time step. The detailed definition of the variables used in Eq. (4), the constitutive relationships for fluidproppant and inter-proppant interactions, and the drag model can be found in Suri et al. (2019).

\subsubsection{Physical model}

The effect of fracture roughness on proppant transport in hydraulic fracture was investigated using the CFD technique in ANSYS FLUENT. The geometry or computational domain used in the current study is, as shown in Fig. 1 and Fig 3. The slurry of proppants suspended in the water is injected with a specified velocity inlet boundary condition. In the real hydraulic fractures which are surrounded by the porous rock, the fluid after entering into the fracture domain leaks into the surrounding reservoir rock. The amount of leakage depends upon the reservoir characteristics such as reservoir porosity and permeability. To evaluate the amount of fluid leakage from the fracture-matrix interface, an explicit CFD study with reservoir porosity $5 \%$ and reservoir permeability $0.5 \mathrm{mD}$ is conducted. The fluid leak-off profile obtained from the analysis is detailed in Fig. 4. The leak-off profile from Fig. 4 is used to write a code in $\mathrm{C}++$ and configure into the CFD solver. The key role of the code is to add source terms into the continuity and momentum conservation equations so that a particular amount of fluid at the fracture wall is lost at every simulation time step. The detailed understanding of the underlying equations describing the source terms and code used to incorporate the effect of dynamic fluid leak-off in proppant transport model is explained in our previous work (Suri et al., 2019). 


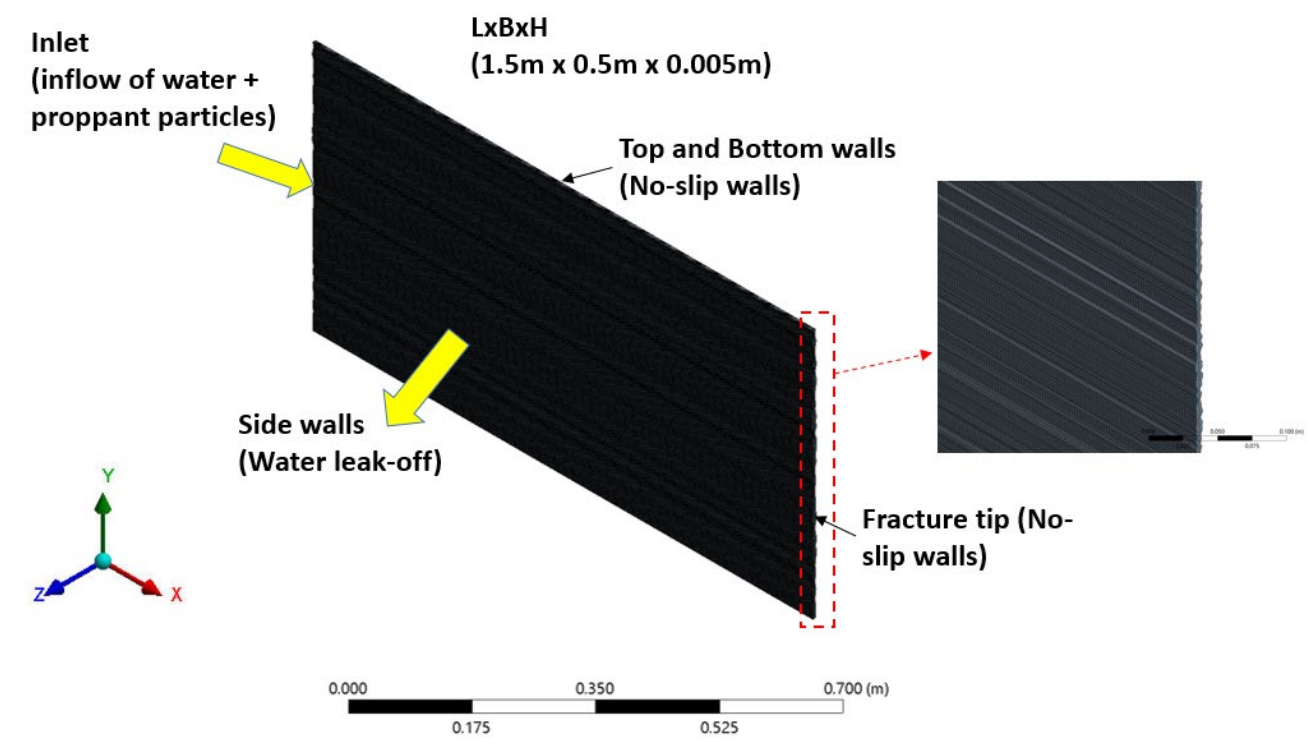

Fig 3. Computational domain

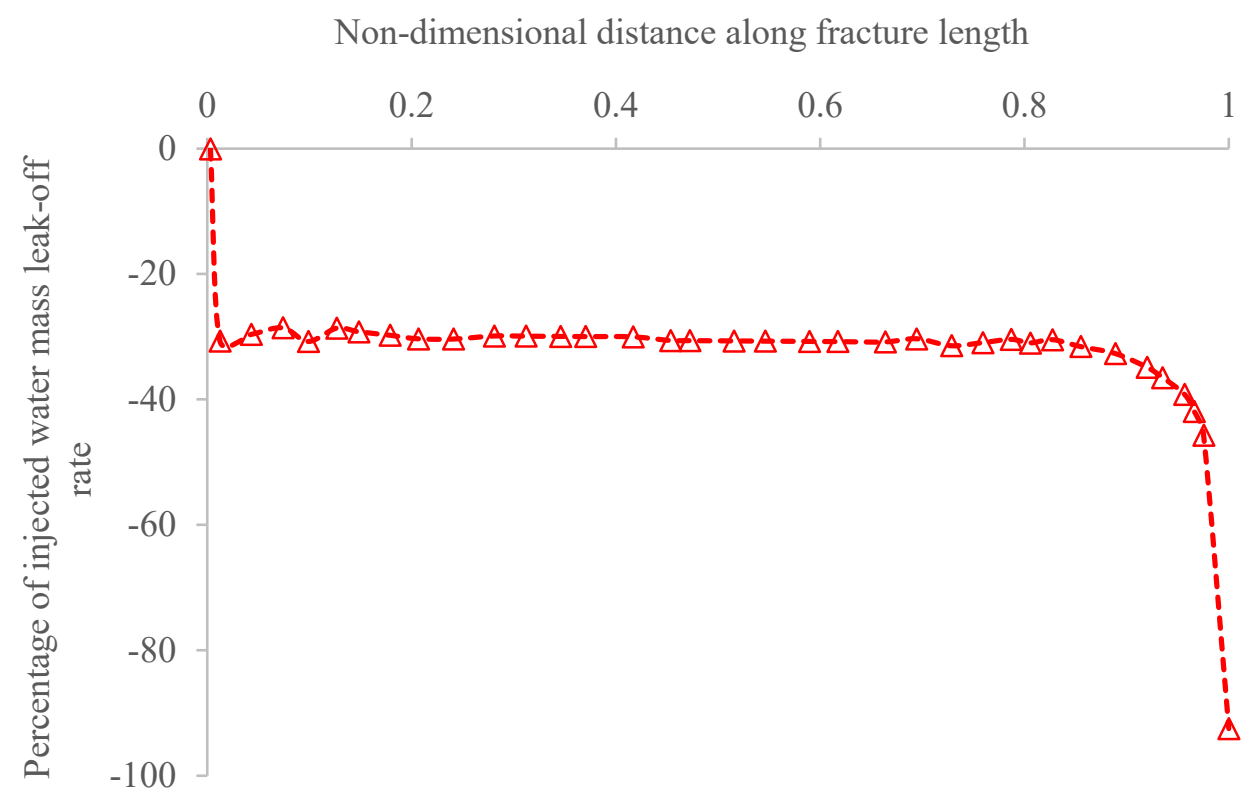

Fig. 4. Amount of fluid leakage at the fracture-matrix interface

Next, to investigate in detail the effect of fracture roughness in proppant transport regime, different proppant and fluid properties are varied one at a time and simulation run with proposed proppant transport model is performed. The key parameters that were varied include proppant size, the injection rate (or injection velocity), fluid viscosity and fracture width for different JRC fracture profiles, as shown in Table 1 . The density of proppants and fluid used in the present study is $2650 \mathrm{~kg} / \mathrm{m} 3$ and $1000 \mathrm{~kg} / \mathrm{m}^{3}$, and the volume fraction of proppants in the slurry was used as $15 \%$. The key CFD modelling specific parameters used in the current model are explained in detail in our previous work (Suri et al., 2019). 
Table 1

Key modelling parameters

\begin{tabular}{ll}
\hline Properties & Value \\
\hline Proppant diameter & $0.35,0.50,0.65 \mathrm{~mm}$ \\
Fluid inlet velocity & $0.1,0.25,0.5 \mathrm{~m} / \mathrm{s}$ \\
Fluid viscosity & $0.0005,0.001,0.005,0.010 \mathrm{~Pa}-\mathrm{s}$ \\
Fracture width & $3,5,10 \mathrm{~mm}$ \\
JRC & 0 (Smooth), $4,8,16$ \\
\hline
\end{tabular}

259

260

261

262

263

264

265

266

267

A mesh sensitivity analysis was conducted such that the solution is independent of the mesh. Proppant volume fraction and axial velocity were compared with different mesh sizing parameters against fracture height at a cross-section plane at $0.5 \mathrm{~m}$ from the inlet and detailed in Fig. 5. The results from the mesh sensitivity study, suggest that the mesh size of $0.0025 \mathrm{~m}$ provides the computationally efficient and mesh independent solution with $(600 \times 200 \times 2$ elements).
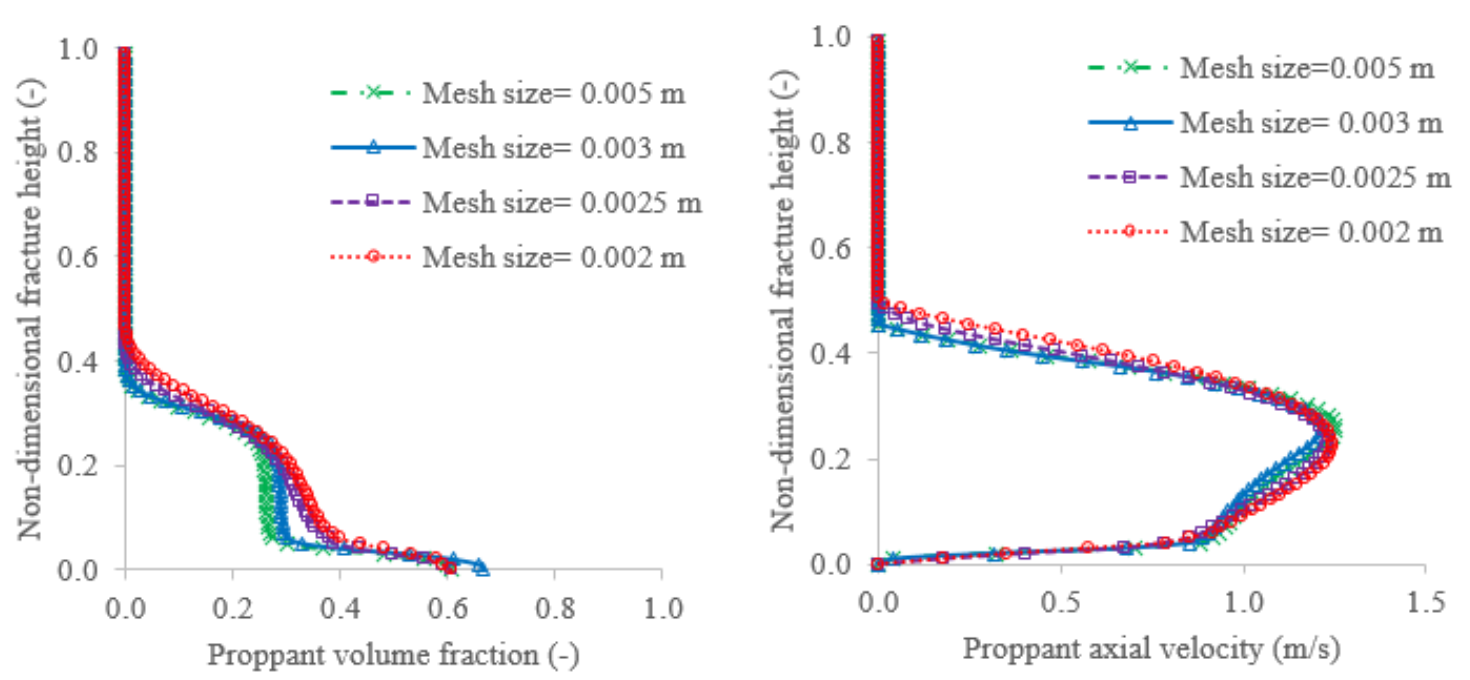

Fig. 5. Mesh Sensitivity Study

2.3. Dimensional analysis

Non-dimensional parameters used in the present study were derived using the dimensional analysis as proposed in Tan (2011). The key parameters that affect the proppant transport and fluid flow in hydraulic fractures are- Proppant properties (proppant size or proppant diameter $d_{p}$, proppant density $\rho_{p}$ ), fracturing fluid properties (fluid viscosity $\mu_{i}$, fluid density $\rho_{l}$, injection flow rate or injection velocity $v_{i}$ ), geo-mechanical parameters (fracture width $w$, fracture roughness $\Theta_{J R C}$, fluid leak-off rate $c_{L}$, (Li et al., 2018). Thus, the proppant distribution, pressure and velocity as a function of flow properties can be written as:

$(\alpha, v, P)=f\left(d_{p}, \rho_{p}, \rho_{l}, v_{i}, \mu_{i}, w, c_{L}, \Theta_{J R C}\right)$

Eq. (5) can be written in the non-dimensional form by using proppant diameter $d_{p}$, injection velocity $v_{i}$ and fracturing fluid density $\rho_{l}$

$$
\left(\alpha, \frac{v}{v_{i,}}, \frac{P}{\rho_{l} \cdot v_{i}^{2}}\right)=f\left(\frac{d_{p}}{w}, \frac{\rho_{p}}{\rho_{l}}, \frac{v_{s}}{v_{r}}, \frac{\rho_{l} \cdot v_{i}, d_{p}}{\mu_{i}}, \frac{\left(\rho_{p}-\rho_{l}\right) \rho_{l} d_{p}^{3} g}{\mu_{i}^{2}}, c_{L}, \Theta_{J R C}\right)
$$


Where, $\frac{\rho_{l} \cdot v_{i} \cdot d_{p}}{\mu_{i}}$ refers to the fraction of inertial force to viscous effects and represents the Reynolds number; and $\frac{\left(\rho_{p}-\rho_{l}\right) \rho_{l} d_{p}^{3} g}{\mu_{i}^{2}}$ is the Archimedes number that describes the ratio of inertia effects to gravity effects.

The density ratio of proppant-to-fluid is constant, and the leak-off rate depends on the reservoir characteristics (porosity and permeability), which are also assumed as constant for a given porosity and permeability. Therefore, Eq. (6) can be re-written as-

$\left(\alpha, \frac{v}{v_{i}}, \frac{P}{\rho_{l} \cdot v_{i}^{2}}\right)=f\left(\frac{d_{p}}{w}, \frac{v_{s}}{v_{r}}, R e, A r, \Theta_{J R C}\right)$

A series of simulation was performed by varying the injection velocity, proppant diameter, fluid viscosity, and fracture roughness one at a time. A detailed investigation of the role of the nondimensional parameters on the proppant transport characteristics was carried out and explained in the following section.

\section{Results and Discussion-}

\subsection{Comparison with the experimental results-}

Tong and Mohanty (2016) performed an experimental study of proppant transport in fracture slots at different injection rates, which was used to compare the numerical results from the present hybrid proppant transport model. The experiment consisted of two transparent fracture slots, as shown in Fig. 6 at different bypass angles. The two different fracture slots represent the interactions between hydraulic fracture and natural fracture. The main fracture slot is called as a primary fracture slot and the bypass fracture slot is called as a secondary fracture slot. The dimensions of the primary fracture slot were $0.381 \mathrm{~m} \times 0.002 \mathrm{~m} \times 0.0762 \mathrm{~m}$ in $\mathrm{L} \times \mathrm{W} \times \mathrm{H}$, and the secondary slot were $0.1905 \mathrm{~m} \times 0.002 \mathrm{~m} \times 0.0762 \mathrm{~m}$ in $\mathrm{L} \times \mathrm{W} \times \mathrm{H}$. The slick water slurry with the suspended proppants is injected using a progressive cavity pump and sand funnel through the inlet located at the right end of the main fracture slot, as shown in Fig. 6. The fracturing fluid slurry (water + proppants) is injected at the inlet at different flow rates or injection velocities $(0.1,0.2$ and $0.3 \mathrm{~m} / \mathrm{s})$ and proppant concentration $(0.038,0.019$, and 0.013$)$. $20 / 40$ size sand is used as a proppant with a density of $2650 \mathrm{~kg} / \mathrm{m}^{3}$. Water is used as a fracturing fluid with viscosity $1 \mathrm{cP}$ and density $1000 \mathrm{~kg} / \mathrm{m}^{3}$. The proppant transport was monitored and recorded with cameras as shown in Fig. 6. The proppant bed deposition after $40 \mathrm{~s}$ of injection for different flow rates (or injection velocities) is compared for both the numerical and experimental results and are shown in Fig. 7. For quantitative comparison, the fraction of proppant deposited in the secondary fracture slot over the primary fracture slot was calculated and plotted at different injection velocities for both, experimental and simulation results, as shown in Fig. 8. The comparison of results in Fig. 7 and Fig. 8 suggests a reasonable match between the numerical simulation and experiment with a percentage error of $3.2 \%$ and $3 \%$ for proppant bed height and length, respectively.

The results suggest an overall good match between the numerical model and experiment, and the model can be used for the detailed investigation of the effect of fracture roughness in the hydrodynamics of proppant transport. 


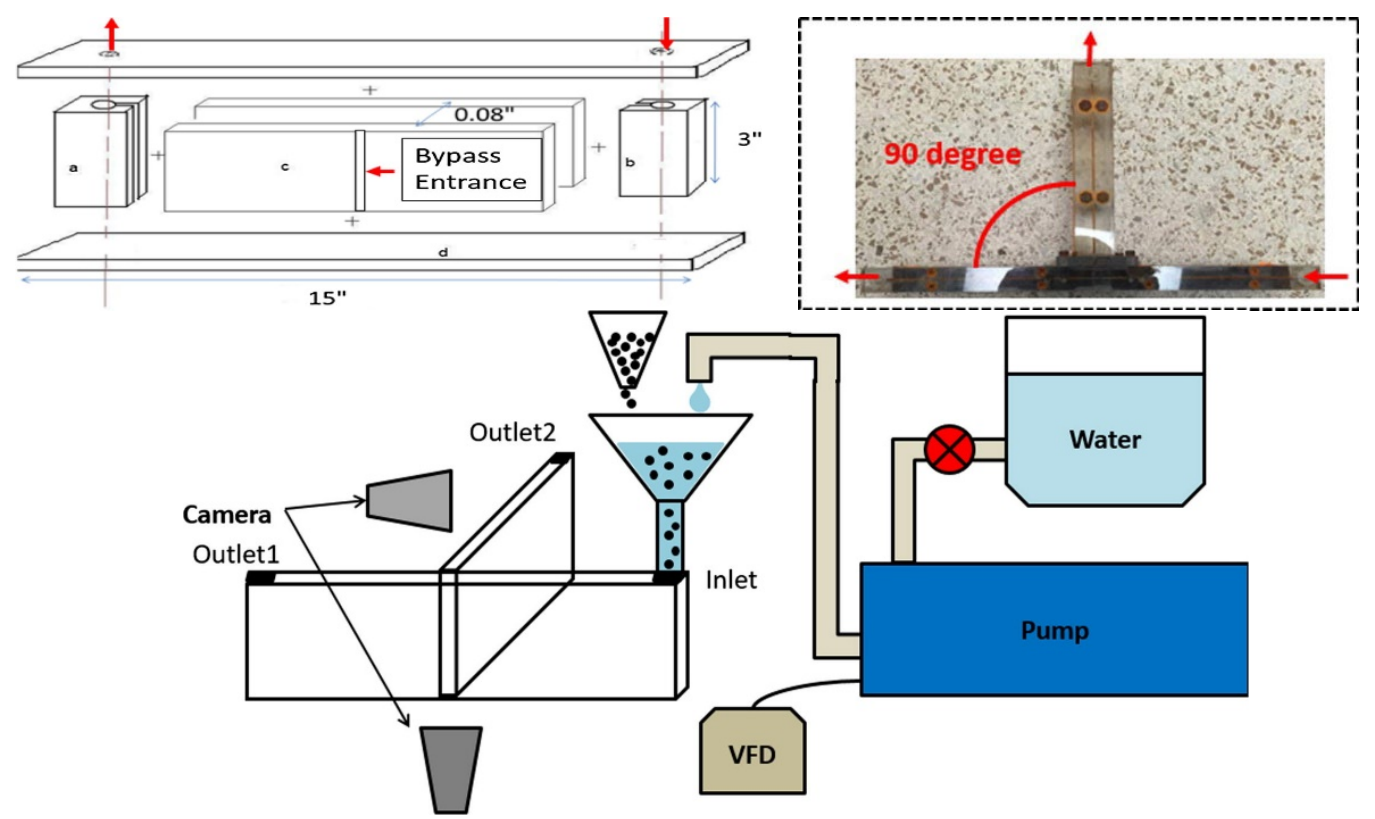

Fig. 6. Schematic of the proppant transport fracture slot experiment (Tong and Mohanty,

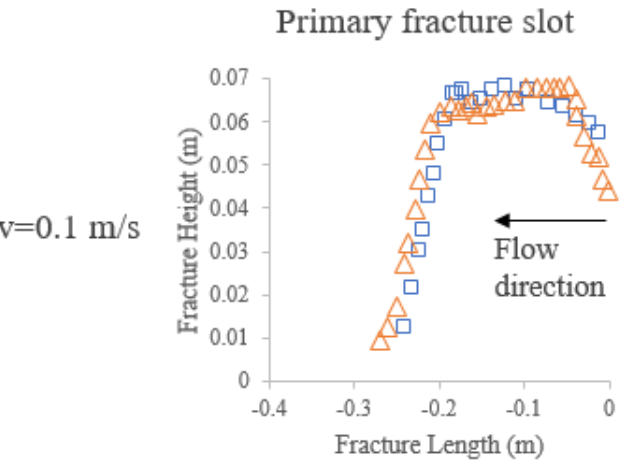
2016)

333
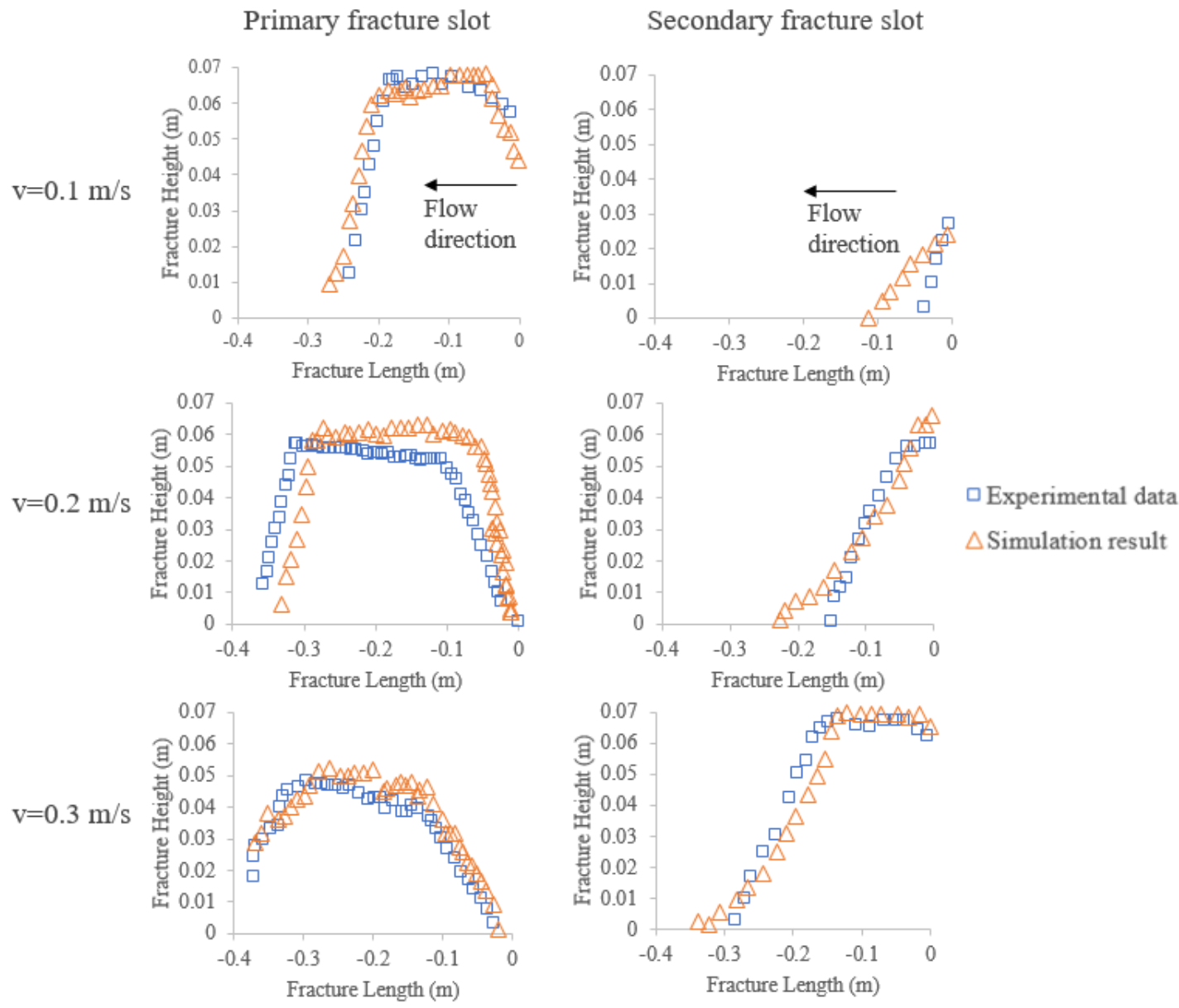

Fig. 7. Comparison of proppant bed deposition at $\mathrm{t}=40 \mathrm{~s}$ 


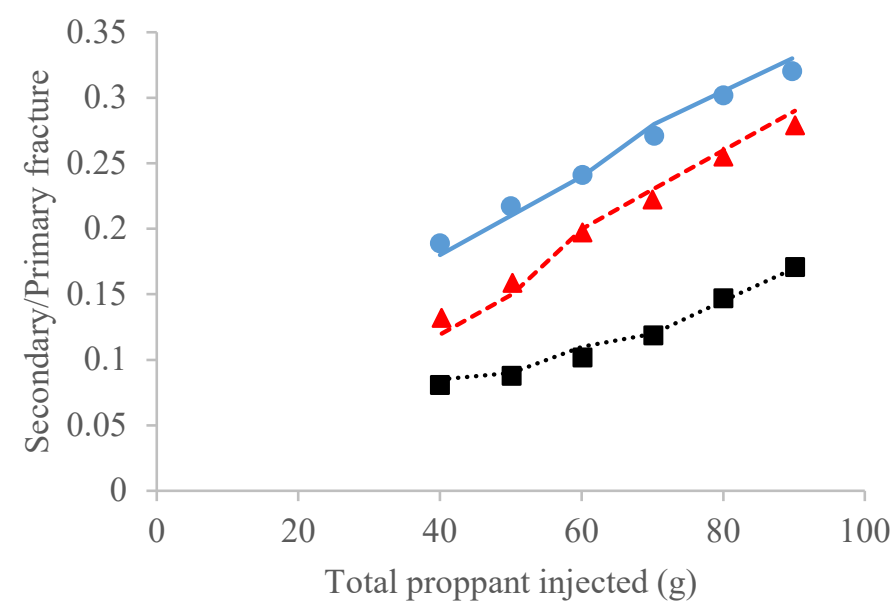
- $\mathrm{v}=0.1 \mathrm{~m} / \mathrm{s}$ Experimental result
$\Delta \quad \mathrm{v}=0.2 \mathrm{~m} / \mathrm{s}$ Experimental result
- $\mathrm{v}=0.3 \mathrm{~m} / \mathrm{s}$ Experimental result
$\mathrm{v}=0.1 \mathrm{~m} / \mathrm{s}$ Simulation result
- - - v $=0.2 \mathrm{~m} / \mathrm{s}$ Simulation result
$-\mathrm{v}=0.3 \mathrm{~m} / \mathrm{s}$ Simulation result

Fig. 8. Quantitative comparison of results - a fraction of proppant deposited in secondary/primary fracture slot at different injection velocities

\subsection{Proppant transport and distribution in smooth fracture}

In the slurry flow, the fracturing fluid carries the proppants inside the fracture, and the fracturing fluid also exerts a drag force on the proppants. Due to the drag force and the energy dissipation, the proppant travels slowly compared to the fluid, and this results in slippage velocity. The proppant motion with fluid can be characterised by the slippage velocity, which is a difference in the fluid and proppant velocity. The slippage velocity depends upon the proppant size and fracturing fluid rheology. Furthermore, when the proppant transport in the hydraulic fractures, the interaction between the proppants and fracture wall affects the horizontal motion. The flow velocity at the centre of the fracture is highest resulting in proppants to transport faster and is smallest near the walls due to non-slip walls, and high shear-induced forces.

To understand the effect of slippage velocity and proppant size ratio on proppant transport, a normalised graph is plotted against variables $\frac{V_{p}-V_{l}}{V}$ and $\frac{d}{w}$ as shown in Fig. 9. Where, $V_{p}-V_{l}$ represents the slippage velocity, $V$ is the characteristic velocity and can be defined by $\sqrt{g d}, \mathrm{~d}$ is the proppant diameter and $\mathrm{w}$ is the fracture width. It can be interpreted from the figure that as the fracture width decreases or proppant diameter increases, the size ratio $\left(\frac{d}{w}\right)$ increases. It results in greater fracture wall retardation effect on proppant motion and consequently decrease in the proppant horizontal transport velocity or slippage velocity.

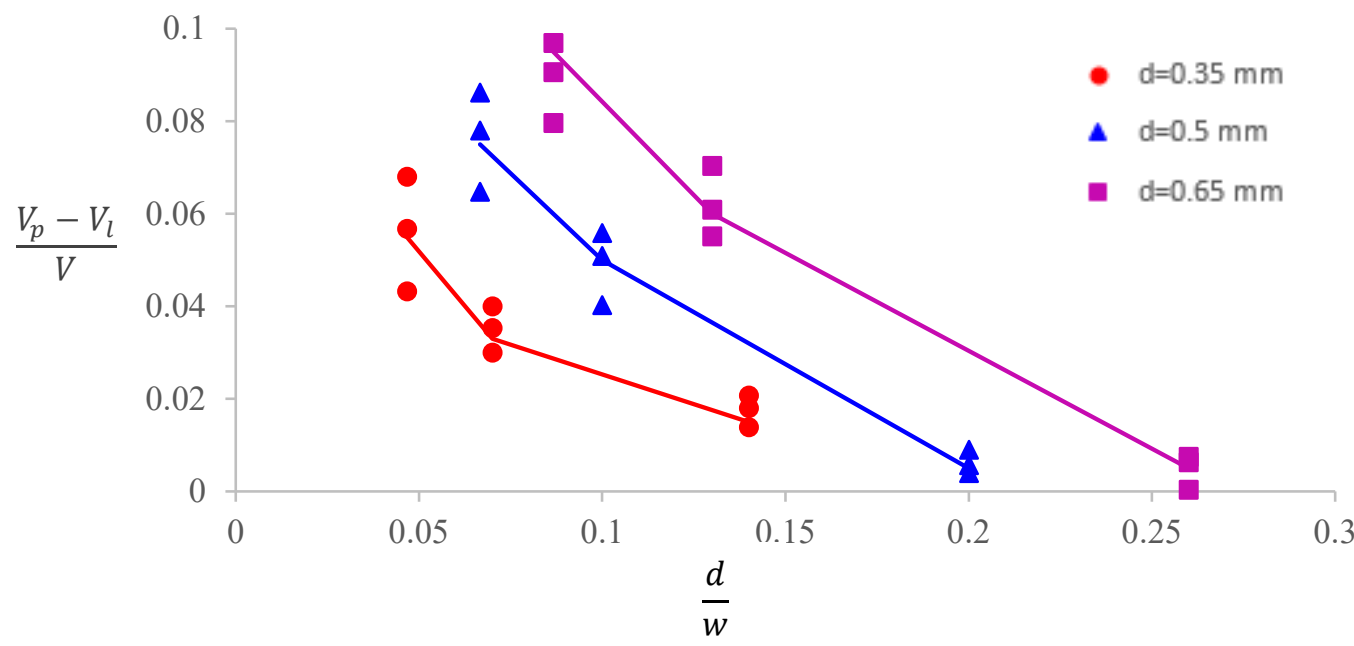

Fig. 9. Variation of slippage velocity with proppant size ratio 
The slippage velocity depends on the injection velocity, proppant size and proppant Reynolds number. Thus, to understand the role of slippage velocity on proppant and fluid properties, two non-dimensional variables were evaluated $R e \cdot \frac{d}{w}$ and $R e \sqrt{\frac{V_{p}}{V_{i n j}}} \cdot R e \cdot \frac{d}{w}$ is a function of proppant size and $\operatorname{Re} \sqrt{\frac{V_{p}}{V_{i n j}}}$ depends on the slippage velocity. The simulation results of all the cases in Table 1 with a smooth fracture profile are plotted on a log-log scale in Fig. 10. It can be interpreted that $R e \cdot \frac{d}{w}$ and $R e \sqrt{\frac{V_{p}}{V_{i n j}}}$ varies linearly in a $\log$-log scale and the power law correlation was defined using the curve fitting, which can be directly used in the fracture simulators to determine the average horizontal velocity of proppants in smooth fractures.

Where $V_{i n j}$ is the injection velocity in $\mathrm{m} / \mathrm{s}$.

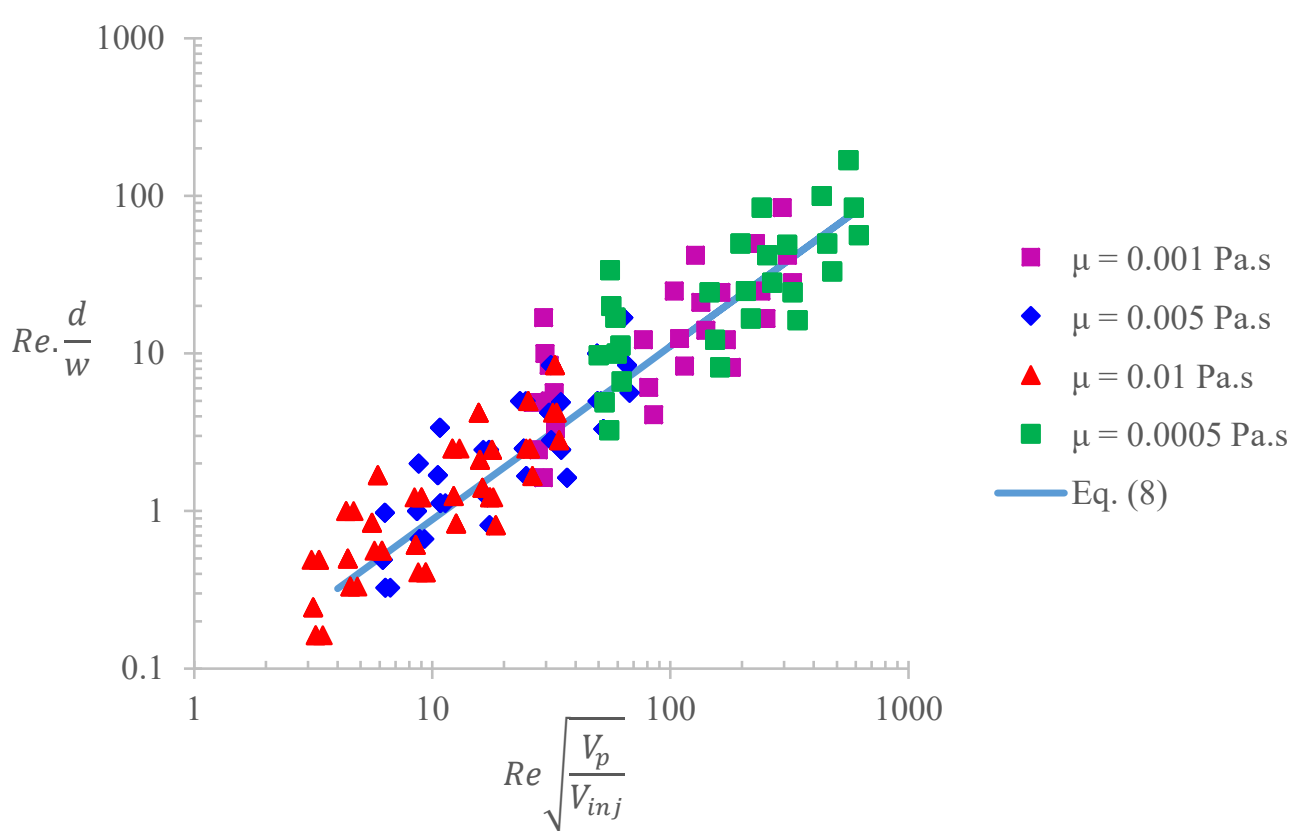

Fig. 10. Log-log plot of correlation between proppant Reynolds number, proppant size ratio and proppant horizontal velocity in smooth fracture

\subsection{Role of fractures roughness on proppant hydrodynamics}

The fracture roughness or the irregular wall surfaces can aid in greater inter-proppant interactions and proppant-fracture wall interaction, which consequently influence the proppant transport and distribution. In order to investigate in detail, the role of fracture roughness in proppant transport regime, understanding of the different fracture roughness and flow parameters is prerequisite. As mentioned earlier, Barton and Choubey (1977) were among the early researchers who studied the fracture roughness in detail and proposed a parameter called Joint Roughness Coefficient to differentiate different rough fractures. The equation for JRC is defined in Eq. (1). In the present study, the rough fractures were created using the JRC profiles from the study of Barton and Choubey (1977) using different JRC profiles and SynFrac software as described earlier. However, the fracture geometries using JRC profiles were created such that it followed a normalised distribution with a mean aperture equal to fracture width. Then the proppant transport was modelled in the rough fractures using the hybrid model (CFDDEM) described earlier, and the simulation results in the form of contour plots are shown in 
Fig. 11. The results in Fig. 11 suggest that fracture roughness plays a significant role in proppant transport. As the JRC increases, it escalates the inter-proppant and proppant-fracture wall interaction. Consequently, it adds that the degree of randomness in the flow to make it more turbulent and complex.

The fracture roughness further affects the hydrodynamic and mechanical behaviours of the proppant flow. The turbulence in the flow due to the fracture roughness increases the ability of proppants to suspend in the fluid and support the proppant to transport longer distance into the fracture. Fig. 11 shows the comparison of vorticity, velocity vector plot and proppant volume fraction plot for different JRC fracture profiles. It can be interpreted from the comparison that with the increase in JRC, it increases the vorticity in the flow due to higher turbulence and flow instability caused by the proppant-wall and inter-proppant collisions. Notably, at the fracture wall, the high vortex region is evident where the proppant frequently collides with the rough fractures leading to higher turbulent kinetic energy and randomness in the flow. This roughness induced turbulence is also evident in the velocity vector plot for different JRC profiles. On comparison of proppant volume fraction contour plot for different JRC profiles, two important observations can be noticed. Firstly, with the increase in JRC value, the increase in the amount of proppant suspension is evident in Fig. 11 by the size of the proppant suspension layer. This suggests that with time, the suspended proppant can be transported further inside the fracture. Thus, neglecting the JRC or effect of fracture roughness could lead to inaccurate estimation of the proppant and fluid velocity into the hydraulic fracturing design. Secondly, for the lower value of JRC or relatively smooth fractures, the fracture wall exerts an additional force or mechanical retardation force on proppants, which slows down the suspended proppants and results in more proppant deposition. This is evident in Fig. 11, where the proppant bed observed in JRC 4 is greater than JRC 8 and JRC 16 fracture profiles. The mechanical retardation effect becomes more dominant, especially in the low viscosity fracturing fluid, like slick water, commonly used in shale gas reservoirs. In the high viscosity fracturing fluid, the effect is less dominant.

JRC

4

8

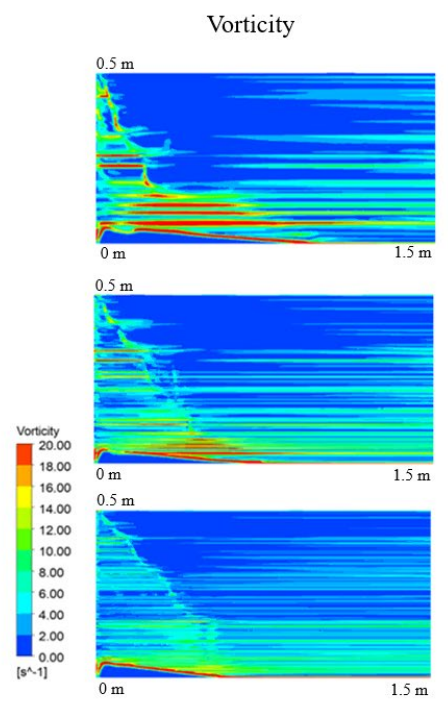

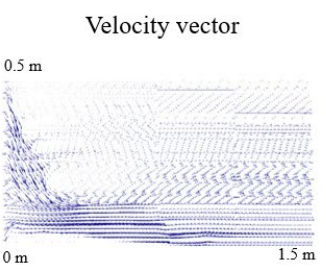

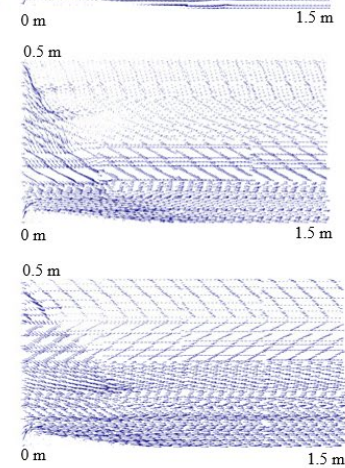

Proppant volume fraction
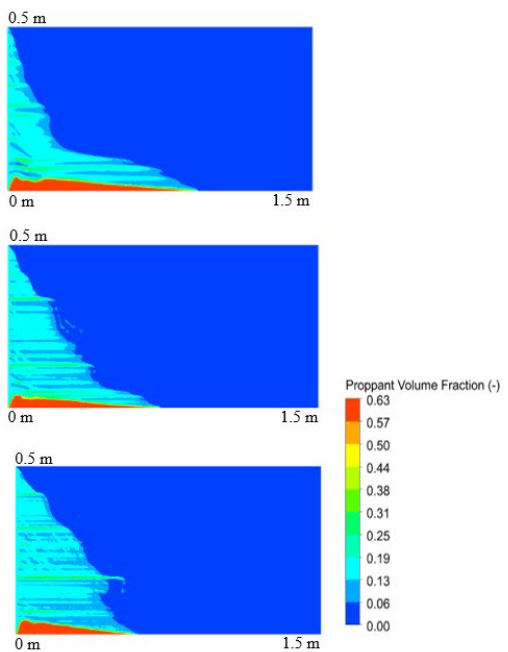

Fig. 11. Comparison of vorticity, velocity vector and proppant volume fraction for different JRC profiles

Next, to investigate the impact of fractures with different JRC profiles on flow regimes, the proppant size and injection rate were varied and compared in Fig. 12 and Fig. 13 respectively. It can be interpreted from Fig. 12 proppant volume fraction plots that proppant particles with greater size form a larger proppant bed compared to smaller size proppants. On the contrary, in terms of proppant suspension, the proppants with smaller size is noted to have a larger suspension region in Fig. 12 proppant volume fraction plot compared to the larger size 
proppants. This can be explained by the proppants with greater size due to its comparatively heavier weight has a higher vertical settling velocity and thus greater tendency to deposit. Conversely, the smaller size proppants due to the lower settling velocity is easily carried away by the flowing fluid and thus resulting in more suspended proppant particles.

Fig. 12 shows that as the injection rate or injection velocity is increased, less proppant deposition is seen in the volume fraction contour plot. This can be explained by the increase in injection velocity results in the increase in the ability of the proppants to suspend and creates randomness in the flow. This further leads to high vorticity in the flow. Thus, a higher number of suspended proppants due to increase in injection velocity can aid in more extended proppant transport.
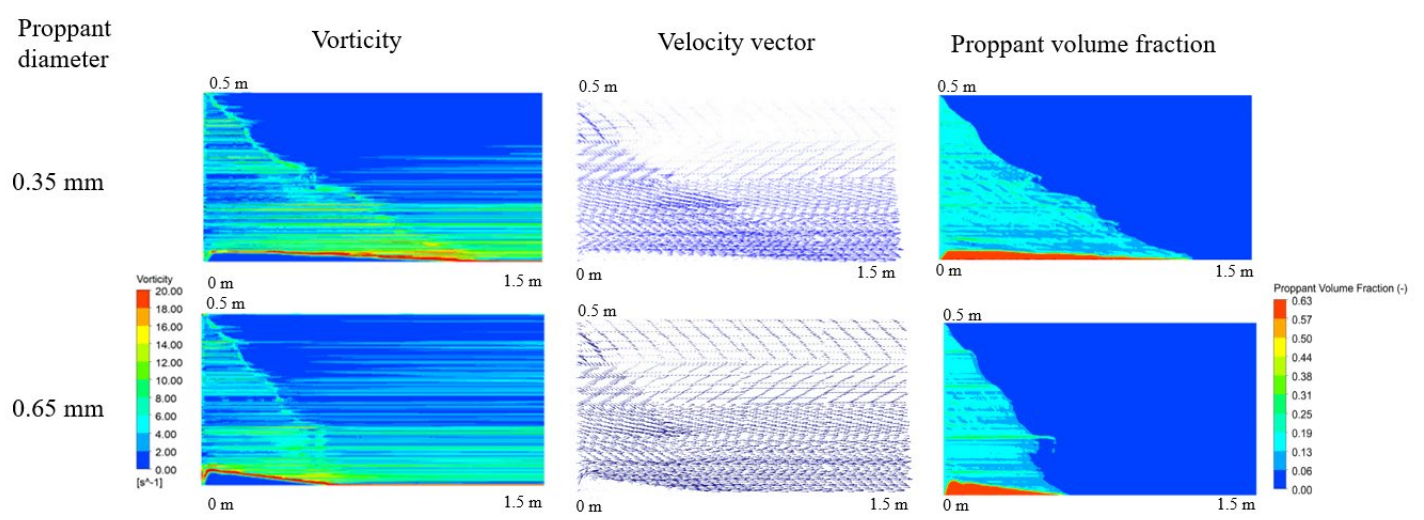

Fig. 12. Comparison of proppant transport in rough fractures with proppant diameter $0.35 \mathrm{~mm}$ and $0.65 \mathrm{~mm}$
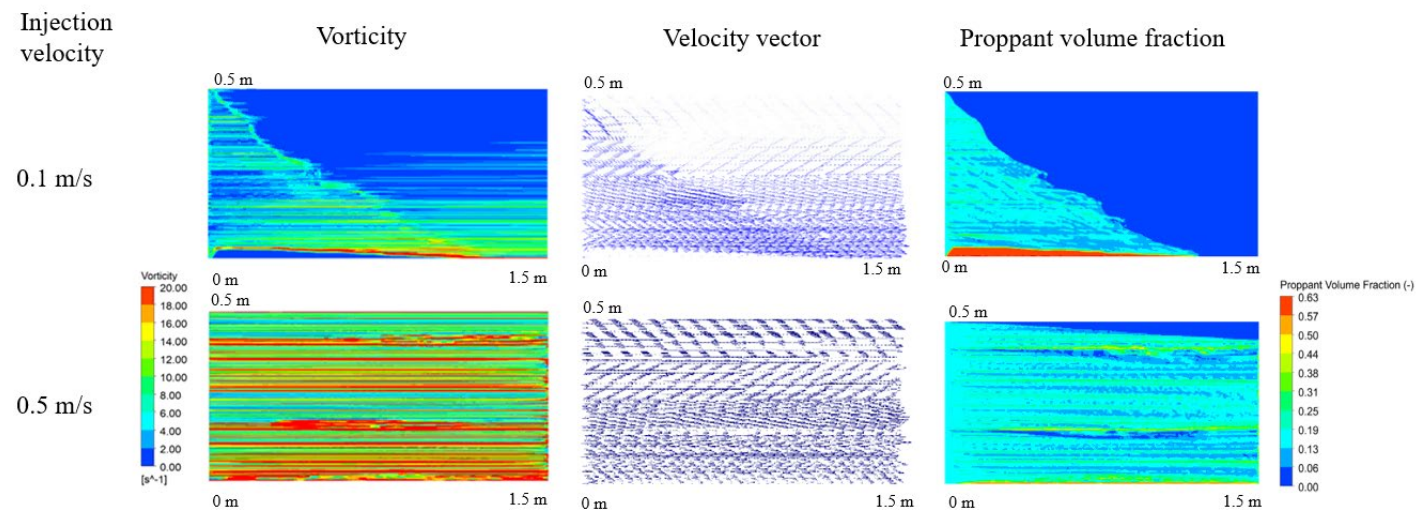

Fig. 13. Comparison of proppant transport in rough fractures with different flow injection velocities

Next, a comparison is made between proppant transport in smooth and rough fracture case with JRC of 16, proppant diameter of $0.65 \mathrm{~mm}$, fluid viscosity of $1 \mathrm{cP}$ and injection velocity of 0.1 $\mathrm{m} / \mathrm{s}$. As explained earlier, it is evident from Fig. 13 that due to the rough fracture wall, the mechanical interaction between the proppant-fracture wall increases and it significantly impacts the vorticity and turbulence in the flow. The increase in the vorticity leads to the higher ability of the slurry to suspend proppants and consequently less deposition of the proppants is seen in terms of proppant bed. 
462

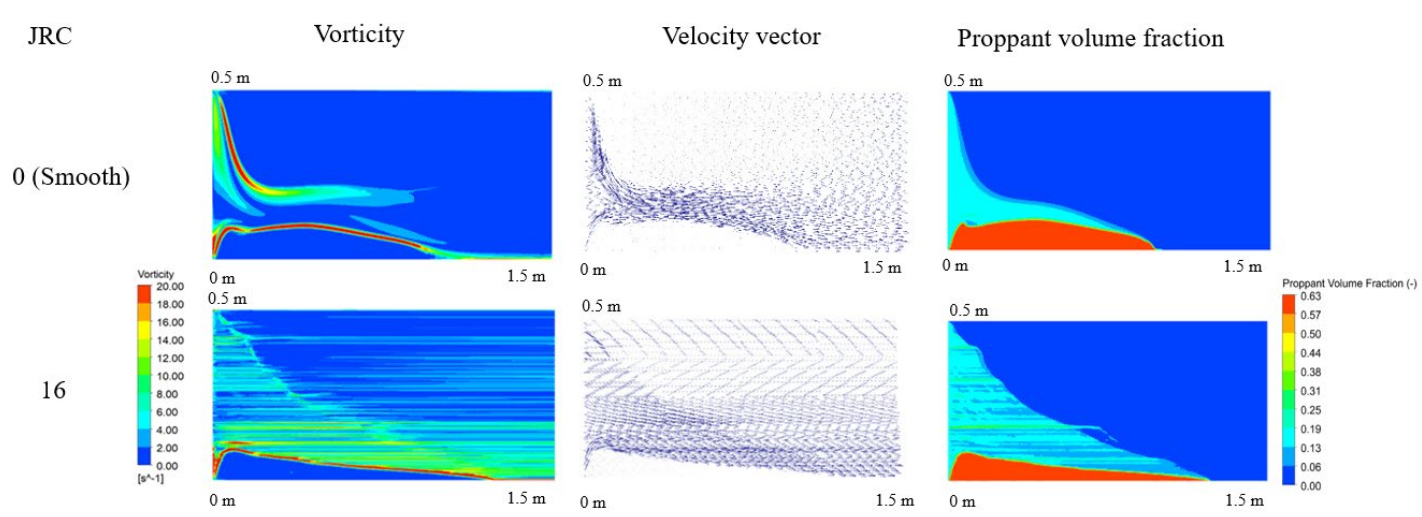

Fig. 14. Comparison of proppant transport in smooth fracture and rough fracture with JRC 16

As analysed above, the fracture roughness plays a significant role in the hydrodynamics of proppant transport, and qualitative comparison of vorticity, longitudinal velocity and volume fraction is shown in Fig. 11-14. Next, to quantitatively investigate the effect of fracture roughness on the proppant transport and distribution, a fracture roughness factor is introduced which is defined as $\in_{R}=\left(v_{s} / v_{r}\right)$. The fracture roughness factor is the ratio of proppant axial velocity in a smooth fracture $\left(v_{s}\right)$ to that in the rough fracture $\left(v_{r}\right)$. A detailed analysis was carried out to investigate the impact of JRC on proppant transport. Different proppant transport simulations were run using the hybrid CFD model explained earlier with varying proppant properties (proppant diameter), flow properties (injection rate and fluid viscosity) and geomechanical properties (fracture roughness JRC and fracture width) one at a time as summarised in Table 1.

Firstly, the effect of JRC fracture profiles on the roughness factor was analysed (Fig. 15). It can be interpreted from Fig. 15 that with the increase in JRC, the roughness factor decreases. This is particularly true under the influence of low injection velocities and higher diameter proppant size (Fig. 15(a-f)). This is due to the increase in fracture roughness results in an increase in the inter-proppant and proppant-fracture wall interactions. Thus, strong mechanical interactions cause more randomness in the flow and accelerate the proppants axial velocity, resulting in the roughness factor $\epsilon_{R}$ below 1 . However, during the proppant transport in high viscosity fluid, the mechanical interaction-induced flow effects do not play a dominant role in proppant horizontal transport, which causes $\epsilon_{R} \approx 1$ and can be ignored, as shown in Fig. 15. Thus, the mechanical interaction-induced effects are strongly dependent on proppant transport regimes (injection velocity, proppant size and fluid viscosity). 

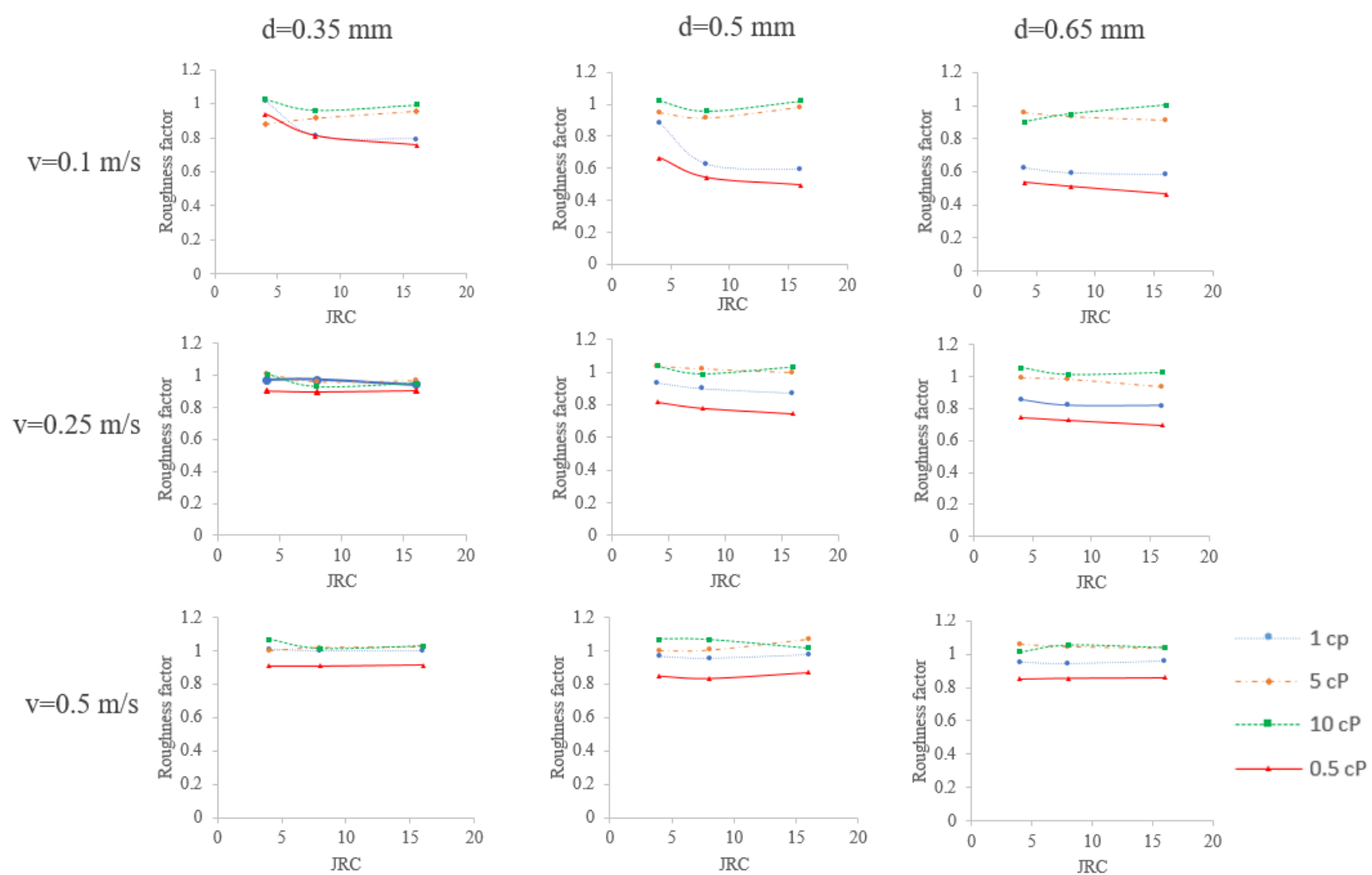

Fig. 15. Variation of fracture roughness factor with JRC for different injection velocity, and

Because of the strong dependence of proppant transport in different flow regime, the transport regions should be defined. A dimensionless composite parameter is introduced $(\mathrm{Ar} / \mathrm{Re})$ which is a ratio of Archimedes number and Reynolds number. The Archimedes number denotes the ratio of buoyancy force to inertia force. Fig. 16 shows the plot between the fracture roughness factor $\epsilon_{R}$ and $\mathrm{Ar} / \mathrm{Re}$, which suggests that for a low value of $\mathrm{Ar} / \mathrm{Re}$, the fracture roughness factor varies mostly independent of $\mathrm{Ar} / \mathrm{Re}$. Conversely, when the ratio of $\mathrm{Ar} / \mathrm{Re}>10$, the fracture roughness factor significantly decreases. This can be explained by when proppants are transported with high-viscous fracturing fluids; the proppant Reynolds number is small. This results in a relatively stable flow field inside the fracture and consequently, low mechanical interaction flow effects. However, when the proppants are transported with low-viscous fluids, the proppant Reynolds number is higher. This results in significantly higher inter-proppant and proppant-wall interactions and consequently increased mechanical interaction flow effects. Thus, proppant horizontal transport is greatly dependent on the fracture roughness and the ratio of $\mathrm{Ar} / \mathrm{Re}$. 


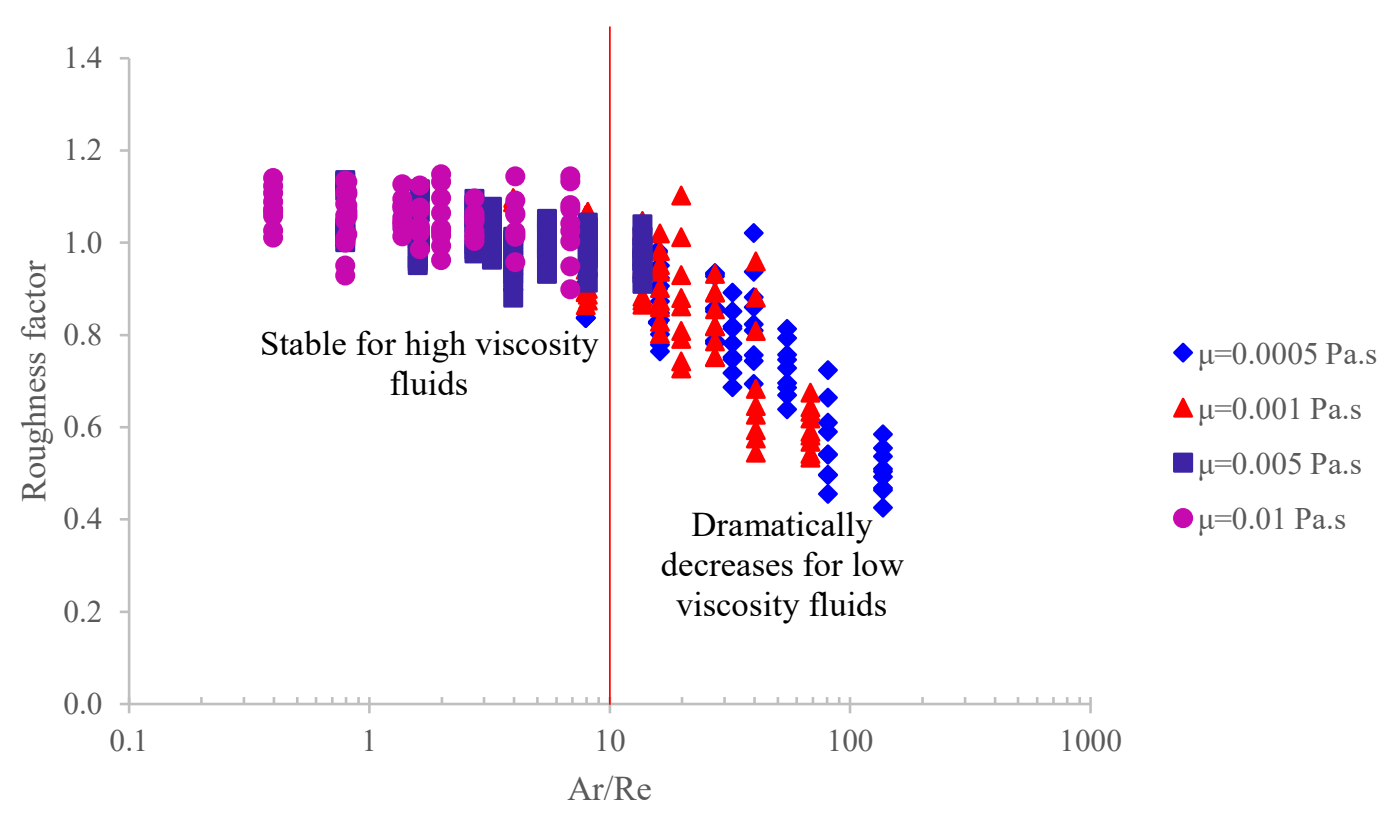

Fig. 16. Semi-log plot of fracture roughness factor with $\mathrm{Ar} / \mathrm{Re}$

Fig. 16 is categorised into two regions based on the variation of fracture roughness factor. In the first region, the fracture roughness factor is almost constant and does not vary much against $\mathrm{Ar} / \mathrm{Re}$ for the range of $\mathrm{Ar} / \mathrm{Re}$ between 0.3 and 10. The fracture roughness factor can be regarded as primarily dependent on JRC, proppant size ratio and injection rate or velocity in this region, and independent of the ratio of Ar/Re. Thus, a non-dimensional parameter $\Theta_{J R C}\left(\frac{d}{w}\right)$ is proposed, and the plot of the roughness factor $\epsilon_{R}$ against the variation in the non-dimensional parameter is shown in Fig. 17. Fig. 17 shows that fracture roughness factor varies linearly with the change of non-dimensional parameter $\Theta_{J R C}\left(\frac{d}{w}\right)$ and Eq. 9 captures the variation of fracture roughness factor against JRC and proppant size ratio for the range of $\mathrm{Ar} / \mathrm{Re}$ between 0.3 and 10.

$$
\frac{V_{s}}{V_{r}}=1-0.0007 * \Theta_{J R C} \frac{d}{w} \quad 0.3 \leq \frac{A r}{R e} \leq 10
$$

From Fig. 16, the second region can be defined where the fracture roughness factor drastically declines as $\frac{A r}{R e}$ increases. This can be explained by when the proppant transport with low viscosity fracturing fluids, the inter-proppant and proppant-wall interactions significantly increases, resulting in higher mechanical interaction flow effects. The increase in fracture roughness further adds to mechanical interactions and consequently, the mechanical interaction flow effects become dominant and gradually governs the proppant transport. Thus, in this region, the fracture roughness factor is dependent upon particle Reynolds number and Archimedes number along with JRC, proppant size ratio and injection rate or velocity. A nondimensional variable that incorporates the effect of $\mathrm{JRC}, \mathrm{Ar} / \mathrm{Re}$, and $\mathrm{d} / \mathrm{w}$ is proposed, $\frac{R e}{\Theta_{J R C} \cdot A r}\left(\frac{w}{d}\right)$, and the plot of the roughness factor $\in_{R}$ against the variation in the nondimensional parameter is shown in Fig. 18. Fig. 18(a) shows that with the increase of the proposed non-dimensional parameter, due to the flow instabilities caused by the fracture roughness and mechanical interaction flow effects, the fracture roughness factor efficaciously increases initially and progressively stabilises to $\epsilon_{R}=1$. To gain a better understanding of the results at a lower value of non-dimensional parameter, the results are plotted on a semi-log scale in Fig. 18(b). To encompass the effect of variation of fracture roughness factor on JRC, $\mathrm{Ar} / \mathrm{Re}$, proppant size ratio and injection velocity, a new relationship is obtained and shown in Eq. (10) that can aid the petroleum engineers to model the proppant transport in rough fractures. 


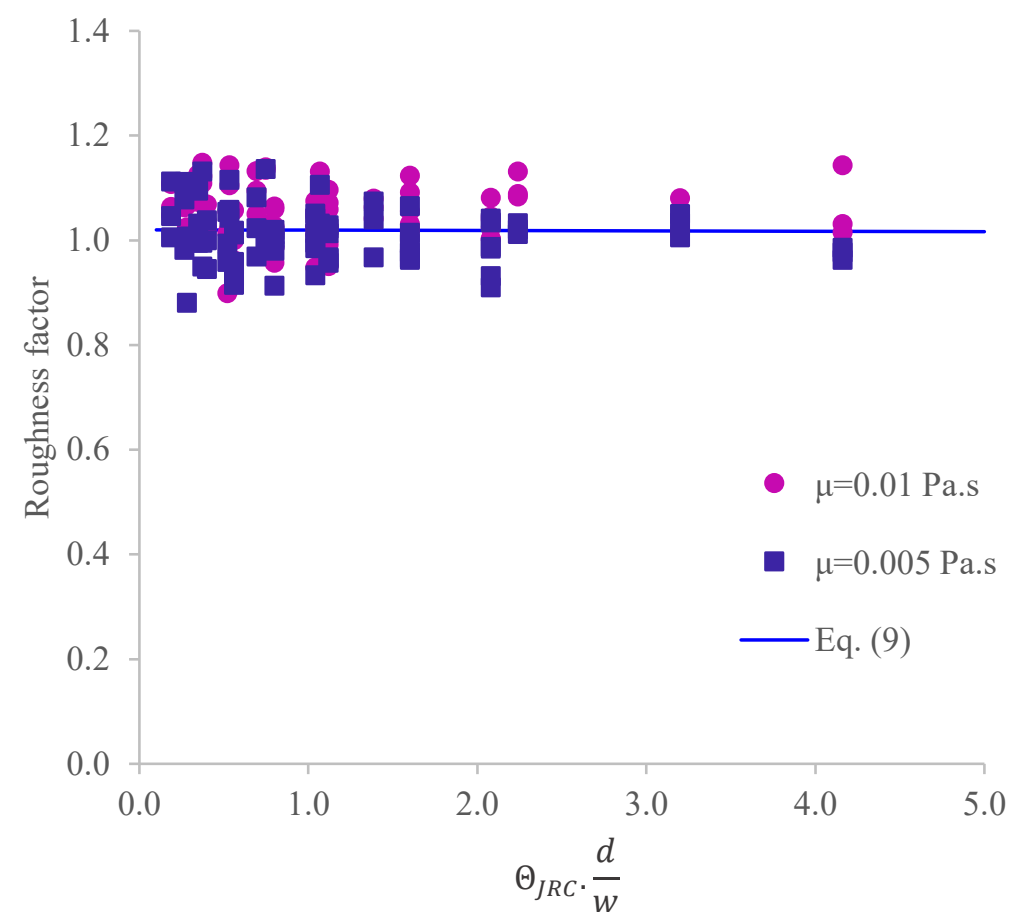

Fig. 17. Variation of fracture roughness factor with $J R C$ and proppant size ratio for $\mathrm{Ar} / \operatorname{Re}<10$

\section{5}

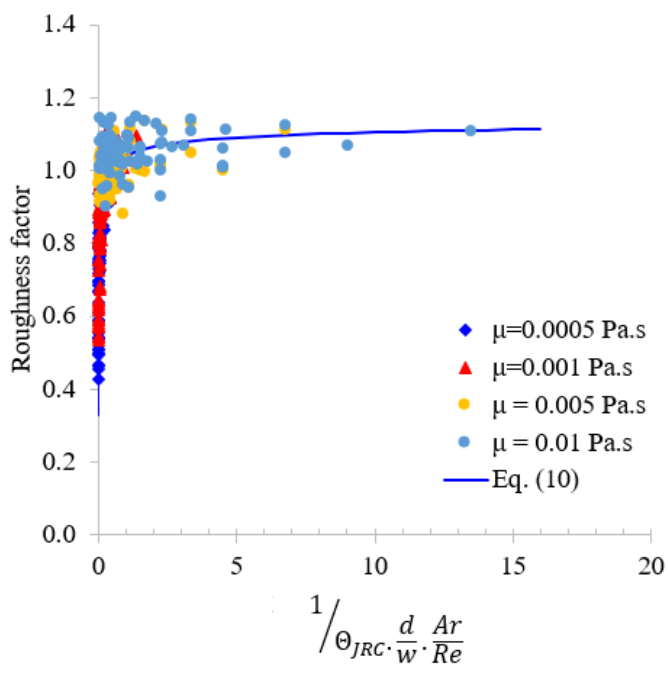

(a)

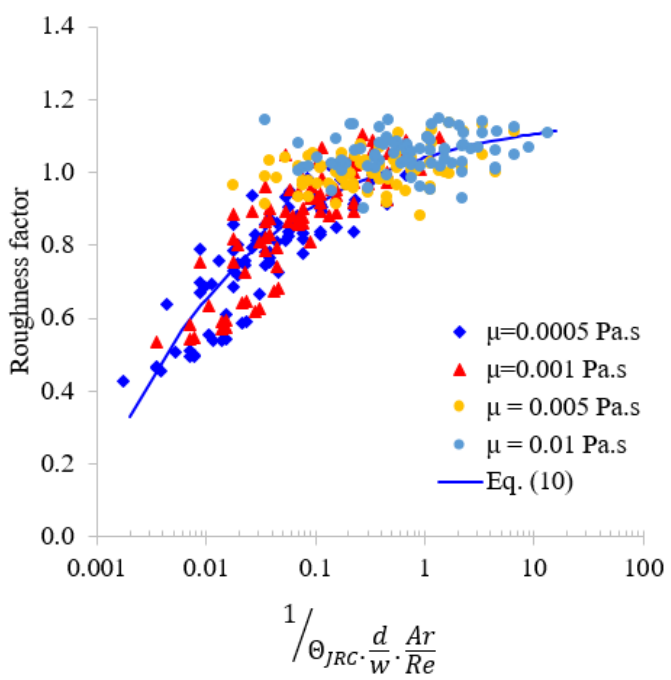

(b)

Fig. 18. Variation of fracture roughness factor with JRC, proppant size ratio and $\mathrm{Ar} / \mathrm{Re}$ for $\mathrm{Ar} / \operatorname{Re}>10$

The correlation developed in the current study from Eq. (9) and Eq. (10) relates to the proppant horizontal transport velocity against the fracture roughness (JRC), flow regime ( $\mathrm{Ar} / \mathrm{Re})$, fluid leak-off effects and proppant size ratio $(\mathrm{d} / \mathrm{w})$ in $3 \mathrm{D}$ fractures. A common assumption widely used during the hydraulic fracturing simulation in shale gas reservoirs and modelling of proppant transport is that the average proppant transport velocity is equal to the carrier fracturing fluid velocity, and the proppant settling velocity follows Stokes' law (Blyton et al., 2018). However, to accurately model the proppant transport and distribution, the effects of fracture roughness, fluid leak-off, drag forces, gravity forces, inter-proppant and proppant- 
fracture wall interactions are required to be incorporated which is not included together in previous assumptions. The proposed correlation was compared against the existing studies, namely Zhang et al. (2019b) and Blyton et al. (2015). Zhang et al. (2019b) investigated the JRC fracture profiles and proposed a proppant transport model in rough fractures. However, the model is limited to two-dimensional fracture geometry, and gravitational effects along with fluid-leak off effects were ignored. The correlation proposed by Zhang et al. (2019b) is shown in Eq. (11). On the other hand, Blyton et al. (2015) comprehensively investigated the proppant transport in hydraulic fractures using CFD-DEM method and proposed a correlation for proppant settling velocity against different proppant size ratio. However, the effect of fracture roughness was ignored in the proppant hydrodynamics. The correlation proposed by Blyton et al. (2015) is shown in Eq. (12).

$$
\begin{aligned}
& \frac{V_{r}}{V_{s}}=\left\{\begin{array}{lr}
1-0.0066 . \Theta_{J R C} \frac{d}{w} \frac{v_{i}}{\sqrt{g d}} & 0.78 \leq \frac{A r}{R e} \leq 11.15 \\
1-\frac{\Theta_{J R C} \cdot \frac{d v_{i}}{w \sqrt{g d}}}{\Theta_{J R C} \cdot \frac{d v_{i}}{w \sqrt{g d}}+238.56 \frac{R e}{A r}} & 11.15 \leq \frac{A r}{R e} \leq 394.92
\end{array}\right. \\
& \frac{V_{p}}{V_{f}}=\left\{\begin{array}{lr}
1 & \frac{d}{w}<0.4 \\
-1.73\left(\frac{d}{w}\right)^{3}+2.45\left(\frac{d}{w}\right)^{2}-0.69\left(\frac{d}{w}\right)+1 & 0.4<\frac{d}{w}<0.95 \\
-21.45\left(\frac{d}{w}\right)+21.45 & \frac{d}{w}>0.95
\end{array}\right.
\end{aligned}
$$

Fig. 19 shows a comparison of the correlation proposed in Eq. (9) and Eq. (10) in the current study with the previous studies of Zhang et al. (2019b) and Blyton et al. (2015). Fig. 19(a) shows the effect of fracture roughness on proppant transport under the influence of high viscosity fracturing fluid. As discussed earlier, when the proppants are transported with highviscous fracturing fluids; the proppant Reynolds number is small. This results in a relatively stable flow field inside the fracture and consequently, low mechanical interaction flow effects. Thus, under the influence of high viscosity fracturing fluid, no significant variation in terms of roughness factor is noticed on comparison of the proposed correlation with the study of Zhang et al. (2019b) and Blyton et al. (2015). On the other hand, Fig. 19(b) shows the effect of fracture roughness on proppant transport under the influence of low viscosity fracturing fluid like slick water, which is commonly used in hydraulic fracturing of shale gas reservoirs. When the proppants are transported with low-viscous fluids, the proppant Reynolds number is higher. This results in significantly higher inter-proppant and proppant-wall interactions and consequently increased mechanical interaction flow effects. Thus, on comparison of the proposed correlation in the current study with the study of Zhang et al. (2019b) and Blyton et al. (2015) shows that since Blyton et al. (2015) ignored the effect of fracture roughness, the turbulence and mechanical interaction flow effects caused due to the increased proppantfracture rough wall interactions were missed in the proppant transport prediction. The proppant transport model proposed by Zhang et al. (2019b) on the other hand, although included the effects of fracture roughness and is able to capture the mechanical interaction flow effects, but is limited to two-dimensional fracture geometry with no gravitational and fluid leak-off effects. On comparison of the current model with the results proposed by Zhang et al. (2019b) in Fig. 19(b) suggests that the results from Zhang et al. (2019b) underpredict by approximately $20 \%$ the proppant transport and distribution due to the assumption of no fluid-leak off, no gravitational effects, and two-dimensional fracture geometry which significantly affects the inter-proppant and proppant-fracture wall interactions. Thus, the applicability of the proposed proppant transport model with fluid leakage and fracture roughness can help petroleum engineers to design the hydraulic fracturing operation with fewer limiting assumptions successfully. 


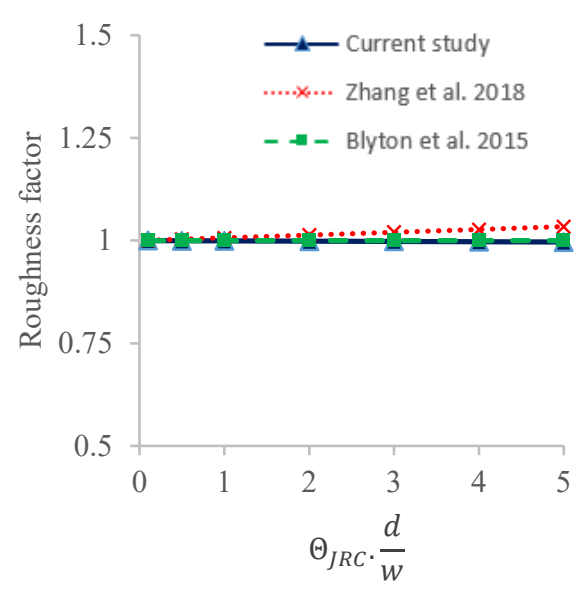

(a)

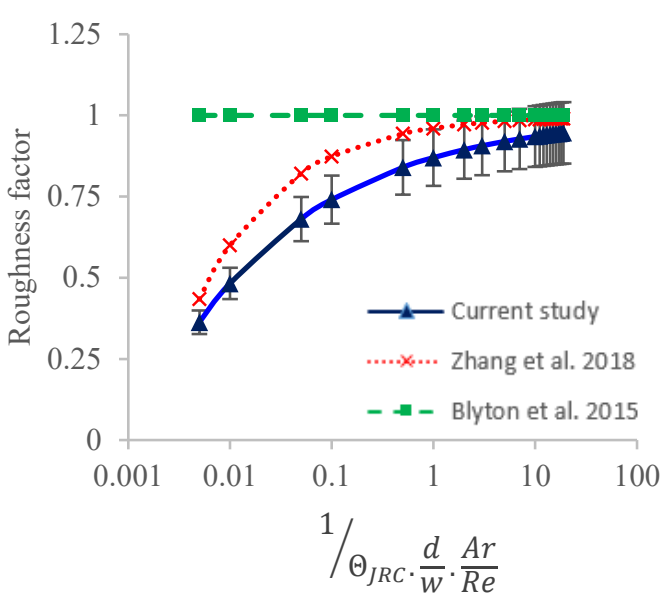

(b)

Fig. 19. Comparison of the proposed correlation with the previous studies (a) for high viscosity fracturing fluid (b) for low viscosity fracturing fluid

The proppant transport in the current study accounts for the effect of fracture roughness, fluid leak-off from the fracture walls, inter-proppant and proppant-fracture wall interactions. As mentioned previously, no dynamic fracture propagation and fracture mechanics is considered in the current model. The current proppant transport model can further be coupled with the dynamic fracture propagation and upscaled to the industrial fractures. However, the proppant transport model developed accounting the integrated effects of fracture roughness, fluid leakoff, inter-proppant and proppant-fracture wall interactions can be incorporated into a complete 3D hydraulic fracture simulation study of shale gas reservoirs. The 3D complete hydraulic fracturing simulation study in shale gas reservoirs will couple the fracture geomechanics, fluid flow and proppant transport in hydraulic fractures to more accurately determine the pressure drop, fluid flow and production efficiency in shale gas reservoirs (Zhang and Sun, 2019). A dynamic and integrated numerical model that uses CFD technique to model the fluid flow with proppant transport and Extended finite element method (XFEM) to model the fracture propagation is discussed in detail in our recent work (Suri et al., 2020b).

In order to investigate the applicability of the current proppant transport model with the real fractures, the current model was compared with the field observations from the hydraulic fracturing in shale gas reservoir. Raterman et al. (2018) investigated the hydraulic fracture propagation from the coring results extracted from a pilot well offset from an adjacent hydraulically fractured well. It was reported that although the stimulated hydraulic fractures were more than $1,000 \mathrm{ft}(305 \mathrm{~m})$, the proppant transport distribution was inefficient and limited to merely $75 \mathrm{ft}(23 \mathrm{~m})$ from the wellbore. Secondly, Kurison et al. (2019a) validated long hydraulic fractures in a carbonate-rich ultra-low permeability reservoir using fracture modelling and observations from chemical tracers, microseismic, pressure interference and reservoir simulation. Furthermore, Kurison et al. (2019b) used data analytics approach to correlate well production performance with hydraulic fracturing stimulation parameters for wells in Eagle Ford and Utica shale reservoirs. Thus, the hydraulic fracture geometry was derived from the Kurison et al. (2019a) study of fracture half-length $800 \mathrm{ft}(245 \mathrm{~m})$ and fracture height of $125 \mathrm{ft}$ $(38 \mathrm{~m})$ to investigate the proppant transport. The fracture width was assumed as $10 \mathrm{~mm}$. Kurison et al. (2019b) provided estimates of average volumes of hydraulic fracturing cluster stimulation for two shale plays. The typical field average for hydraulic fracturing fluid volumes for single perforation clusters in a single wing of the bi-wing fracture is approximately $1500 \mathrm{bbls}$ (equivalent to $3000 \mathrm{bbls}$ fluid volume for a bi-wing fracture). The typical injection time is 60 min, which translates to the fluid flow rate of $36,000 \mathrm{bbl} / \mathrm{d}\left(0.06625 \mathrm{~m}^{3} / \mathrm{s}\right)$. The proppants injected per cluster estimated by Kurison et al (2019b) is 50,000 lbs for a single wing fracture 
(equivalent to $100,000 \mathrm{lbs}$ for a bi-wing fracture). This translates to the proppant concentration of $0.794 \mathrm{lbs} / \mathrm{gal}$. Thus, using this proppant concentration and typical proppant density of 2650 $\mathrm{kg} / \mathrm{m}^{3}$, the proppant volume fraction calculated and used in the model is $3.6 \%$. The key physical properties used in the simulation are detailed in Table 2 which are based on the study of Raterman et al. (2018) and Kurison et al. (2019b). The current hybrid proppant transport model with an assumed JRC of 4 based on the fracture and core images from Raterman et al. (2018) was used in the simulation. The injection time used is $60 \mathrm{~min}$. Fig. 20 shows the result of proppant distribution after $60 \mathrm{~min}$ of injection. The proppant volume fraction plot in Fig. 20 shows that the proppant deposits at the fracture bottom and forms a proppant bed. For the injection time of $60 \mathrm{~min}$, the proppant laterally extends to the entire length of the hydraulic fracture of $245 \mathrm{~m}$. However, in terms of proppant bed height, the average proppant bed height formed after $60 \mathrm{~min}$ of injection is approximately $5.5 \mathrm{~m}$. It is to be noted that once the injection of fracturing fluid stops, the unpropped section of the hydraulic fracture closes down due to the surrounding geomechanical stresses and reservoir pressure. The fracture closure post-injection is not modelled as it is out of the scope of the current study. Additionally, the average proppant horizontal transport velocity is calculated from the numerical simulation at $35 \mathrm{~m}$ from the inlet and compared with the velocity predicted from the Eq. (9) based on the ratio of $\mathrm{Ar} / \mathrm{Re}$. The average proppant horizontal transport velocity from the numerical simulation is $0.21 \mathrm{~m} / \mathrm{s}$ and from the Eq. (9) is $0.205 \mathrm{~m} / \mathrm{s}$, which shows a good agreement and applicability of the current model in simulating the real fractures.

Table 2

Key physical parameters used in the simulation

\begin{tabular}{ll}
\hline Property & Value \\
\hline Fracture dimension & $245 \mathrm{~m} \times 38 \mathrm{~m} \times 0.01 \mathrm{~m}$ \\
Injection rate & $0.06625 \mathrm{~m}^{3} / \mathrm{s}(3600 \mathrm{bbl} / \mathrm{d})$ \\
Proppant size & $0.284 \mathrm{~mm}(40 / 70$ size sand $)$ \\
Proppant concentration & $0.794 \mathrm{bs} / \mathrm{gal}$ \\
Proppant density & $2650 \mathrm{~kg} / \mathrm{m}^{3}$ \\
Proppant volume fraction & 0.036 \\
Slick water density & $1000 \mathrm{~kg} / \mathrm{m}^{3}$ \\
Assumed fluid viscosity & $0.001 \mathrm{~Pa} . \mathrm{s}$ \\
JRC & 4 \\
\hline
\end{tabular}

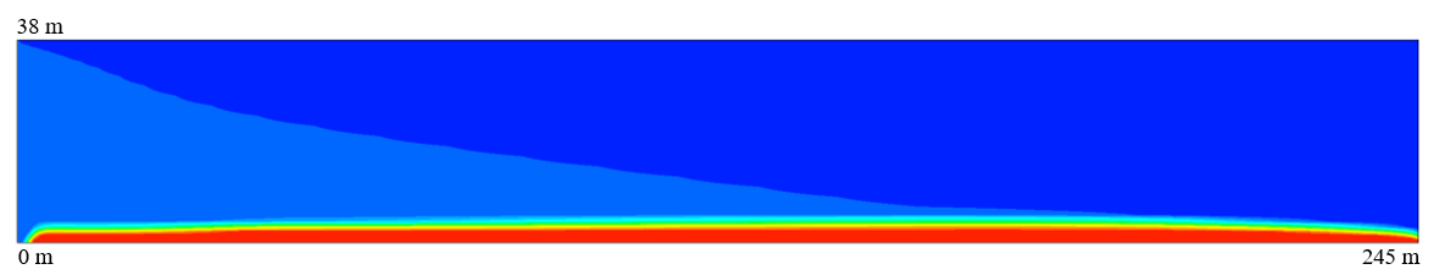

Proppant volume fraction (-)

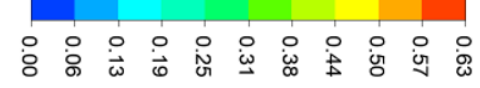

Fig. 20. Proppant transport in industrial-scale hydraulic fracture

667

The proppant transport and distribution in a hydraulic fracture depends on a combination of multiple physical parameters. A detailed discussion of the parametric study about the role of proppant size, injection rate, fluid viscosity and proppant concentration in improving the proppant distribution can be found in our recent work (Suri et al., 2020a, 2020b). In order to improve the proppant transport efficiency firstly, the proppant injection time has to be sufficient enough so that the proppant can successfully distribute to the maximum stimulated hydraulic fracture volume. This can be achieved by correctly modelling the proppant transport physics as detailed in the current model. Secondly, the improvement in the proppant transport sweep 
efficiency in the fracture can be achieved by varying the injection rates or using intermittent injection cycle. This is explained in detail in Suri et al. (2020b) where it was observed that using the multiple cycles of proppant injection followed by flushing pad fluid improved the proppant transport sweep efficiency. Thirdly, another important parameter that significantly improves the proppant transport and distribution is injecting proppants with varying size. Suri et al. (2020a) explained that one of the effective approaches for improving the proppant transport efficiency in the fracture is injecting the fracturing fluid slurry with smaller size proppants followed by larger size proppant particles. This is particularly true for the low viscosity fracturing fluid such as slick water which is commonly used in hydraulic fracturing of shale reservoirs. The smaller size proppants possess a greater suspension ability in the fracturing fluid, and thus injecting the proppant with variation in size results in improved proppant sweep efficiency and can lead to more uniform fracture conductivity (Suri et al., 2020a). Lastly, the fracturing fluid viscosity plays an important role in improving the efficiency of proppant transport (Suri et al., 2020a, 2020b). Suri et al. (2020b) explained that the low viscosity fracturing fluid such as slick water, due to its poor ability for proppant suspension results in a quick deposition of the proppants after injection. This could eventually form a proppant bridge and fracture tip screen-out depending upon the fracture height, which could further lead to a substantial area of fracture remaining unpropped and closing down when the hydraulic pressure is removed. On the contrary, the higher viscosity fracturing fluid due to its better proppant suspension ability can suspend the proppants for a longer period and thus resulting in more extended proppant transport inside the fracture (Suri et al., 2020b). Thus, it can be summarised from the above discussion that the proppant transport efficiency in the hydraulic fracture can be improved using an appropriate combination of injection rate, proppant size, injection time, and fracturing fluid viscosity. The current proppant transport model described in this study can be used to successfully simulate the proppant transport physics by varying different parameters and can aid the petroleum engineers to improve the hydraulic fracturing design.

\section{Conclusions}

Proppant transport and distribution is studied in the rough hydraulic fractures using the Hybrid method (CFD-DEM). The effect of fracture Joint Roughness Coefficient (JRC) was quantitatively investigated on proppant motion. For the fluid flow and proppant transport in smooth fractures, the fracture walls employ substantial mechanical retardation effects on proppants resulting in a decrease of proppant horizontal transport velocity and greater proppant deposition. In contrast, when the proppants are transported in rough fractures, with the increase in fracture roughness the inter proppant and proppant -wall interactions dramatically increase, and consequently higher amount of proppant is suspended in the slurry resulting in greater proppant horizontal transport velocity. Furthermore, in terms of horizontal motion, proppants are inclined to transport a long distance away from the wellbore with the increase in fracture roughness. The mechanical interaction flow effects were found to be dependent on the proppant transport regime. When the proppant transport in high viscosity fluids (i.e. at low proppant Reynolds number), no significant effect of fracture roughness in proppant transport is noticed. In contrast, for proppant transport in low viscosity fluids (i.e. at high proppant Reynolds number), the mechanical interaction effects become dominant with roughness and significantly increases proppant horizontal transport velocity.

\section{Acknowledgement}

The authors are grateful to the School of Engineering, Robert Gordon University, Aberdeen, United Kingdom, for supporting this research.

\section{Conflicts of Interest}

The authors declare no conflicts of interest. 


\section{References}

Alves, L.M., 2012. Foundations of measurement fractal theory for the fracture mechanics, in: Belov, A. (Ed.), Applied Fracture Mechanics. Intech, Bari, pp. 19-66. http://dx.doi.org/10.5772/51813.

Arsenijević, Z.L., Grbavčić, Ž, Garić-Grulović, R., Bošković-Vragolović, N., 2010. Wall effects on the velocities of a single sphere settling in a stagnant and counter-current fluid and rising in a co-current fluid. Powder Technol. 203, 237-242. https://doi.org/10.1016/j.powtec.2010.05.013.

Barton, N., Choubey, V., 1977. The shear strength of rock joints in theory and practice. Rock Mech. 10, 1-54. https://doi.org/10.1007/BF01261801.

Blyton, C.A., Gala, D.P., Sharma, M.M., 2015. A comprehensive study of proppant transport in a hydraulic fracture. In: Paper SPE-174973-MS, SPE Annual Technical Conference and Exhibition, 28-30 September, Houston, Texas, USA. Society of Petroleum Engineers. https://doi.org/10.2118/174973-MS.

Blyton, C.A., Gala, D.P., Sharma, M.M., 2018. A Study of Proppant Transport with Fluid Flow in a Hydraulic Fracture. SPE Drill Completion. 33, 307-323. https://doi.org/10.2118/174973-PA.

Bokane, A.B., Jain, S., Crespo, F., 2014. Evaluation and Optimization of Proppant Distribution in Multistage Fractured Horizontal Wells: A Simulation Approach. In: Paper SPE171581-MS, SPE/CSUR Unconventional Resources Conference - Canada, 30 September-2 October, Calgary, Alberta, Canada. Society of Petroleum Engineers. https://doi.org/10.2118/171581-MS.

Briggs, S., Karney, B.W., Sleep, B.E., 2017. Numerical modeling of the effects of roughness on flow and eddy formation in fractures. J. Rock Mech. Geotec. Eng. 9, 105-115. https://doi.org/10.1016/j.jrmge.2016.08.004.

Chalov, S.R., Jarsjö, J., Kasimov, N.S., Romanchenko, A.O., Pietroń, J., Thorslund, J., Promakhova, E.V., 2015. Spatio-temporal variation of sediment transport in the Selenga River Basin, Mongolia and Russia. Environ. Earth Sci. 73, 663-680. https://doi.org/10.1007/s12665-014-3106-z.

Chhabra, R., Agarwal, S., Chaudhary, K., 2003. A note on wall effect on the terminal falling velocity of a sphere in quiescent Newtonian media in cylindrical tubes. Powder Technol. 129, 53-58. https://doi.org/10.1016/S0032-5910(02)00164-X.

Delidis, P., Stamatoudis, M., 2009. Comparison of the velocities and the wall effect between spheres and cubes in the accelerating region. Chem. Eng. Commun. 196, 841-853. https://doi.org/10.1080/00986440802668182.

Deshpande, Y.K., Crespo, F., Bokane, A.B., Jain, S., 2013. Computational fluid dynamics (CFD) study and investigation of proppant transport and distribution in multistage fractured horizontal wells. In: Paper SPE-165952-MS, SPE Reservoir Characterization and Simulation Conference and Exhibition, 16-18 September, Abu Dhabi, UAE. Society of Petroleum Engineers. https://doi.org/10.2118/165952-MS.

Dontsov, E.V., Peirce, A.P., 2014. Slurry flow, gravitational settling and a proppant transport model for hydraulic fractures. J. Fluid Mech. 760, 567-590. https://doi.org/10.1017/jfm.2014.606.

Hu, X., Wu, K., Li, G., Tang, J., Shen, Z., 2018. Effect of proppant addition schedule on the proppant distribution in a straight fracture for slickwater treatment. J. Pet. Sci. Eng. 167, 110-119. https://doi.org/10.1016/j.petrol.2018.03.081.

Kassis, S., Sondergeld, C.H., 2010. Fracture permeability of gas shale: Effect of roughness, fracture offset, proppant, and effective stress. In: Paper SPE-131376-MS, International oil and gas conference and exhibition, 8-10 June, Beijing, China. Society of Petroleum Engineers. https://doi.org/10.2118/131376-MS.

Kou, R., Moridis, G.J., Blasingame, T., 2018. Field Scale Proppant Transport Simulation and Its Application to Optimize Stimulation Strategy. In: Paper URTEC-2878230MS, SPE/AAPG/SEG Unconventional Resources Technology Conference, 23-25 July 
2018, Houston, Texas, USA. Society of Petroleum Engineers. https://doi.org/10.15530/urtec-2018-2878230.

Kurison, C., Kuleli, H.S., Mubarak, A.H., Al-Sultan, A., Shehri, S.J., 2019a. Reducing uncertainty in unconventional reservoir hydraulic fracture modeling: A case study in Saudi Arabia. J. Nat. Gas Sci. Eng. 71, 102948. https://doi.org/10.1016/j.jngse.2019.102948.

Kurison, C., Kuleli, H.S., Mubarak, A.H., 2019b. Unlocking well productivity drivers in Eagle Ford and Utica unconventional resources through data analytics. J. Nat. Gas Sci. Eng. 71, 102976. https://doi.org/10.1016/j.jngse.2019.102976

Li, P., Zhang, X., Lu, X., 2018. Numerical simulation on solid-liquid two-phase flow in cross fractures. Chem. Eng. Sci. 181, 1-18. https://doi.org/10.1016/j.ces.2018.02.001.

Malhotra, S., Sharma, M.M., 2012. Settling of spherical particles in unbounded and confined surfactant-based shear thinning viscoelastic fluids: An experimental study. Chem. Eng. Sci. 84, 646-655. https://doi.org/10.1016/j.ces.2012.09.010.

Mandelbrot, B.B., 1983. The fractal geometry of nature. WH freeman, New York.

Ogilvie, S.R., Isakov, E., Glover, P.W., 2006. Fluid flow through rough fractures in rocks. II: A new matching model for rough rock fractures. Earth Planet. Sci. Lett. 241, 454-465. https://doi.org/10.1016/j.epsl.2005.11.041.

Patankar, N.A., Joseph, D.D., 2001. Modeling and numerical simulation of particulate flows by the Eulerian-Lagrangian approach. Int. J. Multiph. Flow. 27, 1659-1684. https://doi.org/10.1016/S0301-9322(01)00021-0.

Raterman, K.T., Farrell, H.E., Mora, O.S., Janssen, A.L., Gomez, G.A., Busetti, S., McEwen, J., Friehauf, K., Rutherford, J., Reid, R., 2018. Sampling a Stimulated Rock Volume: An Eagle Ford Example. SPE Reserv. Evaluation Eng. 21, 927-941. https://doi.org/10.2118/191375-PA.

Sahai, R., Miskimins, J.L., Olson, K.E., 2014. Laboratory results of proppant transport in complex fracture systems. In: Paper SPE-168579-MS, SPE Hydraulic Fracturing Technology Conference, 4-6 February, The Woodlands, Texas, USA. Society of Petroleum Engineers. https://doi.org/10.2118/168579-MS.

Sahu, A., Tripathy, A., Biswal, S., 2013. Study on particle dynamics in different cross sectional shapes of air dense medium fluidized bed separator. Fuel. 111, 472-477. https://doi.org/10.1016/j.fuel.2013.04.011.

Smith, M.B., Montgomery, C., 2015. Hydraulic fracturing. CRC Press, Boca Raton, Florida. https://doi.org/10.1201/b16287.

Speight, J.G., 2016. Handbook of Hydraulic Fracturing. John Wiley \& Sons, Inc., Hoboken, New Jersey. https://doi.org/10.1002/9781119225102.

Suri, Y., Islam, S.Z., Hossain, M., 2019. A new CFD approach for proppant transport in unconventional hydraulic fractures. J. Nat. Gas Sci. Eng. 70, 102951. https://doi.org/10.1016/j.jngse.2019.102951.

Suri, Y., Islam, S.Z., Hossain, M., 2020a. Numerical modelling of proppant transport in hydraulic fractures. Fluid Dyn. Mater. Process. 16, 297-337. https://doi.org/10.32604/fdmp.2020.08421.

Suri, Y., Islam, S.Z., Hossain, M., 2020b. Proppant transport in dynamically propagating hydraulic fractures using CFD-XFEM approach. Int. J. Rock Mech. Min. Sci. 131, 104356. https://doi.org/10.1016/j.ijrmms.2020.104356.

Tan, Q., 2011. Dimensional analysis: with case studies in mechanics. Springer Science \& Business Media, Berlin. https://doi.org/10.1007/978-3-642-19234-0.

Tong, S., Mohanty, K.K., 2016. Proppant transport study in fractures with intersections. Fuel. 181, 463-477. https://doi.org/10.1016/j.fuel.2016.04.144.

Uddameri, V., Morse, A., Tindle, K.J., 2015. Hydraulic fracturing impacts and technologies: A multidisciplinary perspective. CRC Press, Boca Raton, Florida. https://doi.org/10.1201/b18581

Veatch, R.W., King, G.E., Holditch, S.A., 2017. Essentials of hydraulic fracturing: Vertical and horizontal wellbores. PennWell Corporation, Tulsa, Oklahoma. 
Zhang, G., Zhang, Y., Xu, A., Li, Y., 2019a. Microflow effects on the hydraulic aperture of https://doi.org/10.26804/ager.2019.01.09.

Zhang, G., Gutierrez, M., Chao, K., 2019b. Hydrodynamic and mechanical behavior of multiparticle confined between two parallel plates. Adv. Powder Technol. 30, 439-450. https://doi.org/10.1016/j.apt.2018.11.023.

Zhang, G., Gutierrez, M., Li, M., 2017. A coupled CFD-DEM approach to model particle-fluid mixture transport between two parallel plates to improve understanding of proppant micromechanics in hydraulic fractures. Powder Technol. 308, 235-248. https://doi.org/10.1016/j.powtec.2016.11.055.

Zhang, G., Li, M., Xue, J., Wang, L., Tian, J., 2016. Wall-retardation effects on particles settling through non-Newtonian fluids in parallel plates. Chem. Pap. 70, 1389-1398. https://doi.org/10.1515/chempap-2016-0082.

Zhang, J., Dunn-Norman, S., 2015. Computational fluid dynamics (CFD) modeling of proppant transport in a plug and perf completion with different perforation phasing. In: Paper URTEC-2169184-MS, Unconventional Resources Technology Conference, 20-22 July 2015, San Antonio, Texas, USA. Society of Petroleum Engineers. https://doi.org/10.15530/urtec-2015-2169184.

Zhang, T., Sun, S., 2019. A coupled Lattice Boltzmann approach to simulate gas flow and transport in shale reservoirs with dynamic sorption. Fuel. 246, 196-203. https://doi.org/10.1016/j.fuel.2019.02.117.

\section{Nomenclature}

$\overrightarrow{\mathrm{F}}_{\mathrm{KTGF}}$

$\overrightarrow{\mathrm{M}}_{\mathrm{ls}}$

Inter-particle interaction force from kinetic theory of granular flow

$\epsilon_{R}$

$\mathrm{C}_{\mathrm{D}}$

Interfacial momentum transfer

$\mathrm{S}_{\mathrm{m}}$

Fracture roughness factor

$\mathrm{S}_{\mathrm{u}}$

Drag coefficient

Mass source term

Momentum source term

$\overrightarrow{\mathrm{V}}$

Velocity

$\tau_{\mathrm{r}}$

Particle relaxation time

$\Phi_{b}$

$V_{\text {inj }}$

Basic friction angle

Injection velocity

$c_{L}$

Fluid leak-off rate constant

$v_{r}$

Velocity in rough fracture

$v_{s}$

Velocity in a smooth fracture

Fracture compressive strength

$\sigma_{c}$

$\sigma_{n}$

$\mathrm{Ar}$

CFD

d

Effective normal stress

Archimedes number

Computational fluid dynamics

Proppant diameter (size)

DEM

Discrete element method

$\mathrm{g}$

Acceleration due to gravity

JRC Joint roughness coefficient

KTGF Kinetic theory of granular flow

$\mathrm{P}$

Pressure

$\operatorname{Re}$

Reynolds number

$\mathrm{t}$

Current time step

UDF

User-defined function

$\mathrm{w}$

Fracture width 


$\begin{array}{lll}889 & \alpha & \text { Volume fraction } \\ 890 & \mu & \text { Dynamic viscosity } \\ 891 & \rho & \text { Density } \\ 892 & \tau & \text { Maximum shear strength } \\ 893 & \Theta_{J R C} & \text { Joint roughness coefficient } \\ 894 & & \\ 895 & \text { Subscripts: } & \\ 896 & \mathrm{i} & \text { Phase (liquid or solid) } \\ 897 & \mathrm{l} & \text { Liquid phase } \\ 898 & \mathrm{p} & \text { Particle phase } \\ 899 & \mathrm{~s} & \text { Granular phase }\end{array}$

